\title{
Deployment Operation Procedures for the WHOI Ice-Tethered Profiler
}

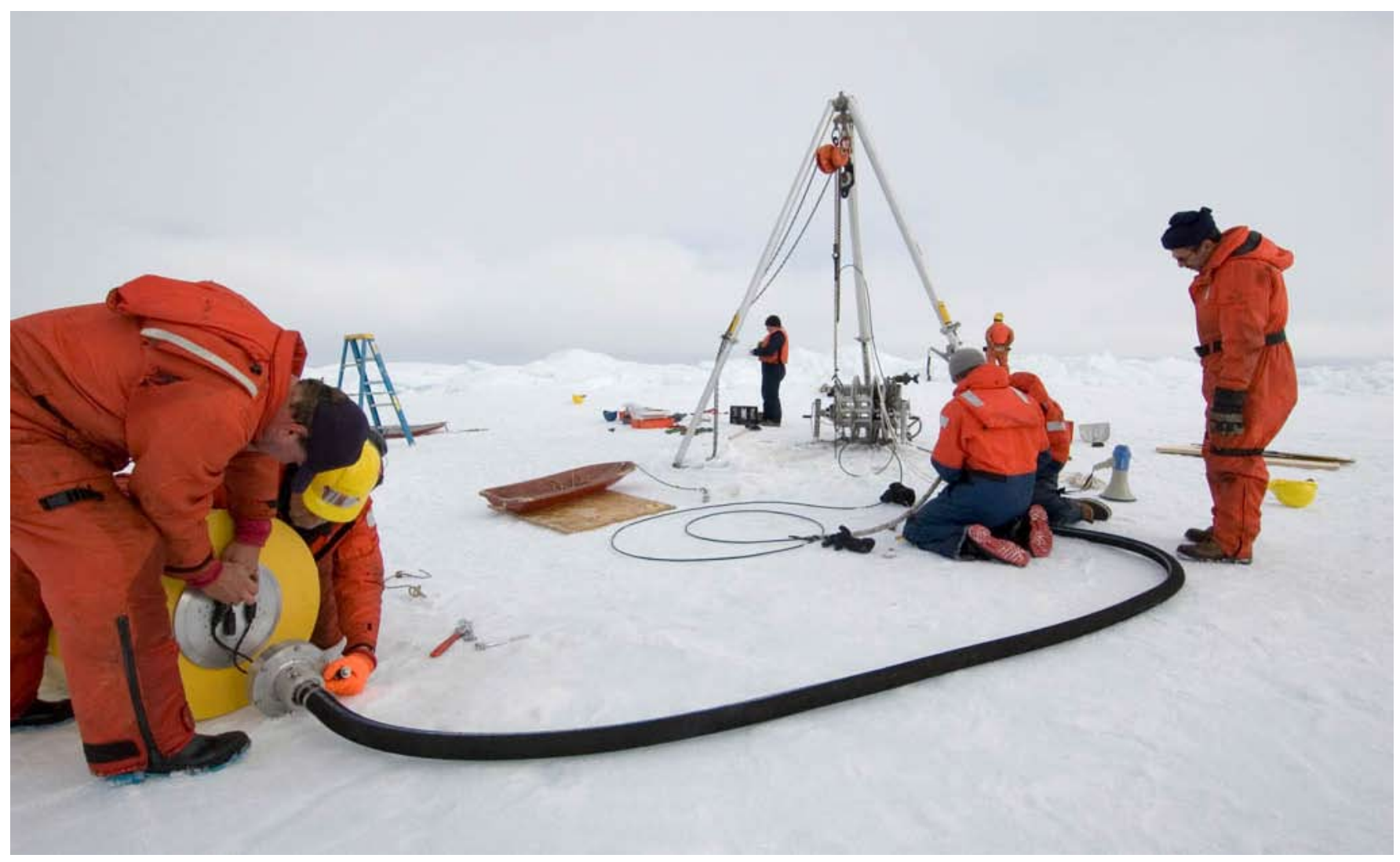

by

K. Newhall, R. Krishfield, D. Peters, and J. Kemp

May 2007

Woods Hole Oceanographic Institution

Woods Hole MA

\section{Technical Report}

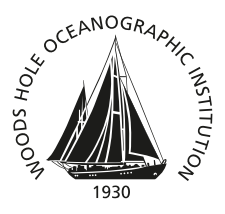




\section{WHOI-2007-05}

\section{Deployment Operation Procedures for the WHOI Ice-Tethered Profiler}

by

K. Newhall, R. Krishfield, D. Peters, and J. Kemp

July 2007

\section{Technical Report}

Funding was provided by the National Science Foundation under Grant No. OCE-0324233 and by the Office of Polar Programs under award numbers ARC-0519899 and ARC-0631951.

Reproduction in whole or in part is permitted for any purpose of the United States Government. This report should be cited as Woods Hole Oceanog. Inst. Tech. Rept., WHOI-2007-05.

Approved for public release; distribution unlimited.

Approved for Distribution:

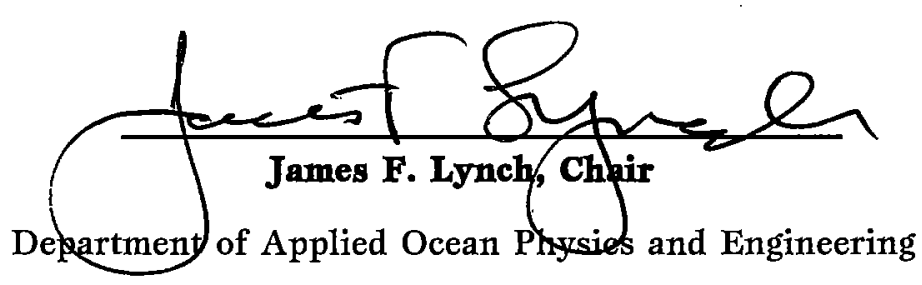


This page intentionally left blank 


\section{TABLE OF CONTENTS}

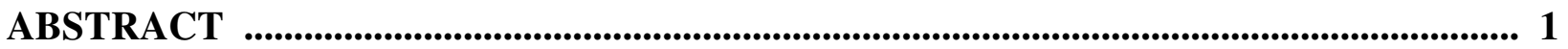

BACKGROUND

ICE TETHERED PROFILER .......................................................... 3

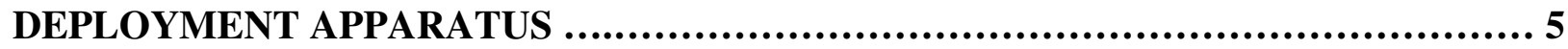

Winch Mechanical Design ......................................................... 5

Handling Gear ............................................................................. 9

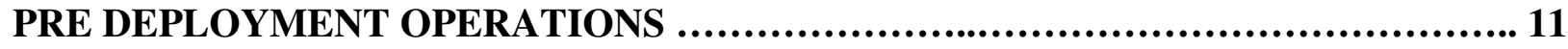

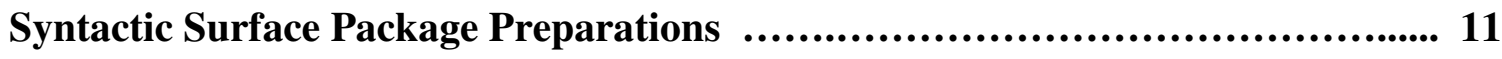

Ice Tethered Profiler Preparations .................................................. 11

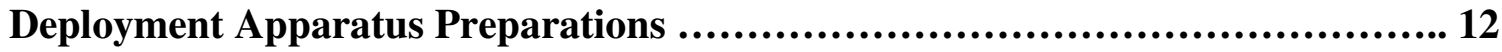

The Winch Assembly ........................................................... 12

Deployment site selection, survey, and analysis .............................. 16

DEPLOYMENT OPERATIONS ....................................................... 19

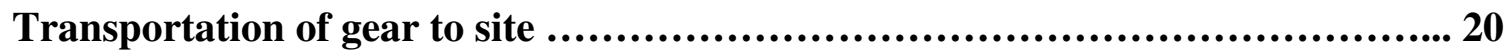

Drilling operations and Tripod Setup .......................................... 21

Winch Operation and Placement ........................................... 24

ITP Installation ................................................................... 25

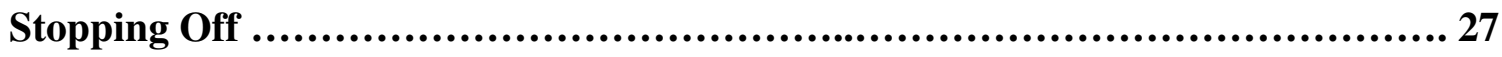

Slipping positions and procedures .............................................. 29

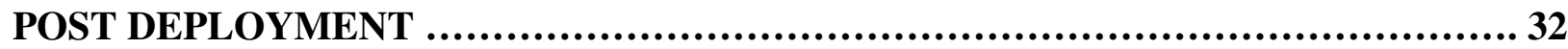

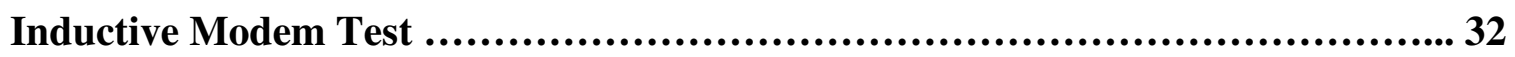

Site Break Down and Clean Up ................................................ 35

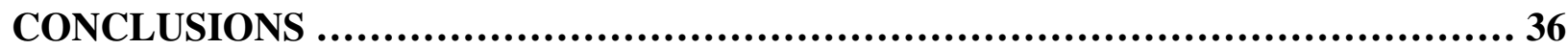

ACKNOWLEDGEMENTS ....................................................... 38

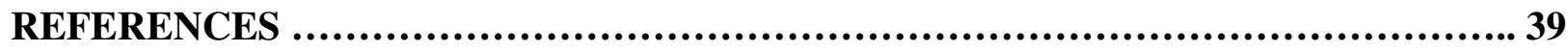

APPENDIX: ITP Deployment Checklist $\ldots \ldots \ldots \ldots \ldots \ldots \ldots \ldots \ldots \ldots \ldots \ldots \ldots \ldots \ldots \ldots \ldots \ldots \ldots \ldots \ldots \ldots . . . . \ldots$ 


\section{LIST OF FIGURES}

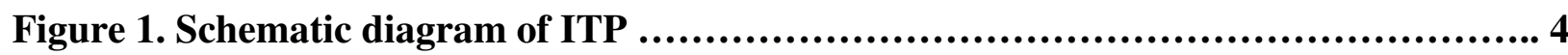

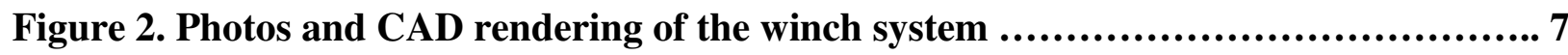

Figure 3. Engineering drawing showing winch overall dimensions ............................ 9

Figure 4. Winch system components with ITP tether preloaded ......................... 12

Figure 5. Satellite imagery of ice concentrations and locations in the Beaufort Sea ........ 17

Figure 6. With armed protection, the 2"' hole is drilled during the ice survey .............. 18

Figure 7. Drilling operations using the tripod and chain hoist for assistance ................ 22

Figure 8. Correct positioning of the winch in relation to the deployment hole .............. 23

Figure 9. Wire-anchor connection along with the correct placement of the bumper ...... 26

Figure 10. Clove hitch placement for supporting the ITP on the wire rope ............... 27

Figure 11. Mechanical connection between the strength member and surface package... 29

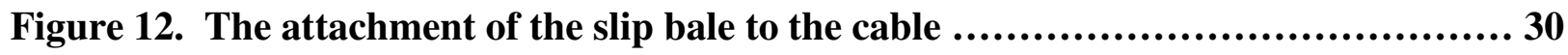

Figure 13. A 'Yale Grip' is used to lower the mooring until the slip bale is used ........... 31

Figure 14. Using the cleat to slip the final section of the mooring into place ............... 32

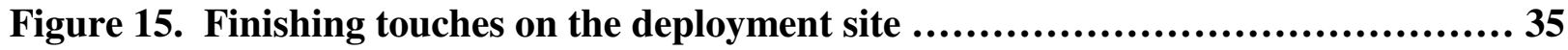




\section{LIST OF TABLES}

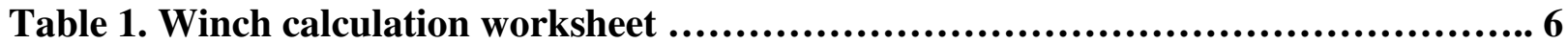

Table 2. Total weights for deployment gear .............................................. 10

Table 3. Itemized ITP deployment parts list .............................................. 14

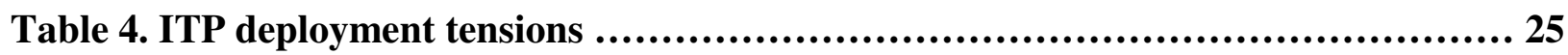




\section{ABSTRACT}

Deployed and fixed to a suitable multi-year ice floe, the Ice-Tethered Profiler (ITP) can sustain near-real time measurements of upper ocean temperature and salinity for up to three years. Incorporating a specifically designed winch system and deployment apparatus that is both light weight and easily assembled or disassembled on a ship or at a deployment site, the ITP can be deployed in less than four hours by either transporting the gear and field personnel to the deployment site via aircraft, or by lowering the gear over the side of a ship and hauling on the ice. Using daily satellite imagery (if available), visual reconnaissance flights, and ice surveying, the choice of an appropriate ice floe is a necessity to select a site that will sustain the system for a prolonged period of time (depending upon the instrument sampling rate). If available, the helicopter is the preferable method for surveying different sites and for deployment operations. Working from a ship typically limits the distance and selection of ice floes. Pre-deployment procedures include powering and configuring the ITP instruments and preparing the apparatus for transport to the deployment site. Specific deployment methods include the assembly and disassembly of the ITP winch, proper placement of the total ITP deployment apparatus, 'Yale Grip' braiding and slipping techniques, and testing the Iridium and Inductive communication links. The operations described here provide a safe and efficient manner to easily deploy the WHOI ITP. 


\section{BACKGROUND}

The International Polar Year (IPY) in 2007-08 will be well served by technological innovations since the last international concentrated scientific and exploring program in the Polar Regions during the International Geophysical Year in 1957-58. Today, satellite remote sensing technology is providing daily atmosphere and sea ice data from even the most remote regions of the Arctic and Antarctic. Icebreakers and aircraft provide unprecedented access to the Polar Regions, and advances in microprocessor, robotics, and telephone communication technologies have enabled the development of a variety of automated data acquisition devices.

Because the historical observational archive of the Arctic is thin (in comparison to the temperate latitudes), the coupled evolution of the atmosphere-ice-ocean system is still poorly understood. Manned operations in the Arctic are far more difficult and expensive than at lower latitudes, and the perennial sea ice cover precludes the use of standard profiling and/or acoustically-tracked expendable floats (though variants of these instruments show promise for sampling the marginal and seasonal ice zones). This observational gap represents a critical shortcoming of the envisioned "global" ocean observing system, this at a time when evidence is mounting that a complex suite of significant, interrelated, atmospheric, oceanic, and terrestrial changes are now underway in the Arctic, affecting every part of the Arctic environment and having increasing repercussions on society.

One of the observational tools represented in the new National Academy of Sciences report: "Towards an Integrated Arctic Observing Network" (IAON); (available from http://www.nap.edu/catalog/11607.html) and in the SEARCH ("Study of Environmental Arctic Change") Implementation Workshop report (SEARCH, 2005) are Ice-Based Observatories (IBOs). Several prototype IBO systems have been fielded in recent years including: 
- $\quad$ the IABP buoy array accompanied by US CRREL Ice Mass Balance (IMB) buoys (http://iabp.apl.washington.edu/, http://www.crrel.usace.army.mil/sid/IMB/);

- $\quad$ the JAMSTEC Compact Arctic Drifter (J-CAD) and Polar Ocean Profiling System (POPS) buoys in combination with IMB buoys (http://www.jamstec.go.jp/arctic/JCAD_e/jcadindexe);

- the North Pole Environmental Observatory (http://psc.apl.washington.edu/northpole);

- $\quad$ and most recently, WHOI Ice-Tethered Profilers (ITPs) together with IMB and Arctic Ocean flux buoys (AOFB); http://www.whoi.edu/itp/, http://www.oc.nps.navy.mil/ stanton/fluxbuoy/).

Presently, construction and installation of an array of IBOs consisting of ITPs with IMBs and some AOFBs is underway due to a combined international effort including the European Union DAMOCLES program (http://www.damocles-eu.org), Alfred Wegener Institute in Germany, Arctic and Antarctic Research Institute in Russia, and the US National Science Foundation Office of Polar Programs as a contribution to the Arctic Observing Network (AON) during the IPY. This report describes the specially designed deployment apparatus and detailed installation procedure to install ITPs on multiyear ice floes.

\section{ICE TETHERED PROFILER}

The automated easily-deployed ITP has been developed to economically be deployed on perennial sea ice in polar oceans to measure changes in upper ocean temperature and salinity in all seasons (Toole et al., 2006; Krishfield et al., 2006). The ITP consists of three main 
subsystems: a surface electronics package that is placed atop an appropriate ice floe, a wire-rope tether up to $800 \mathrm{~m}$ in length with a $\sim 100 \mathrm{~kg}$ ballast weight at the bottom (all of which is supported by the surface package and ice floe), and a neutrally-buoyant underwater instrument unit that propels itself up and down along the tether transporting oceanographic sensors through the water column.

The surface package is enclosed within a cylinder of Surlyn foam floatation that provides modest protection against ice ridging and is able to buoy the whole system should the supporting ice floe fracture. The standard ITP instrument carries a CTD

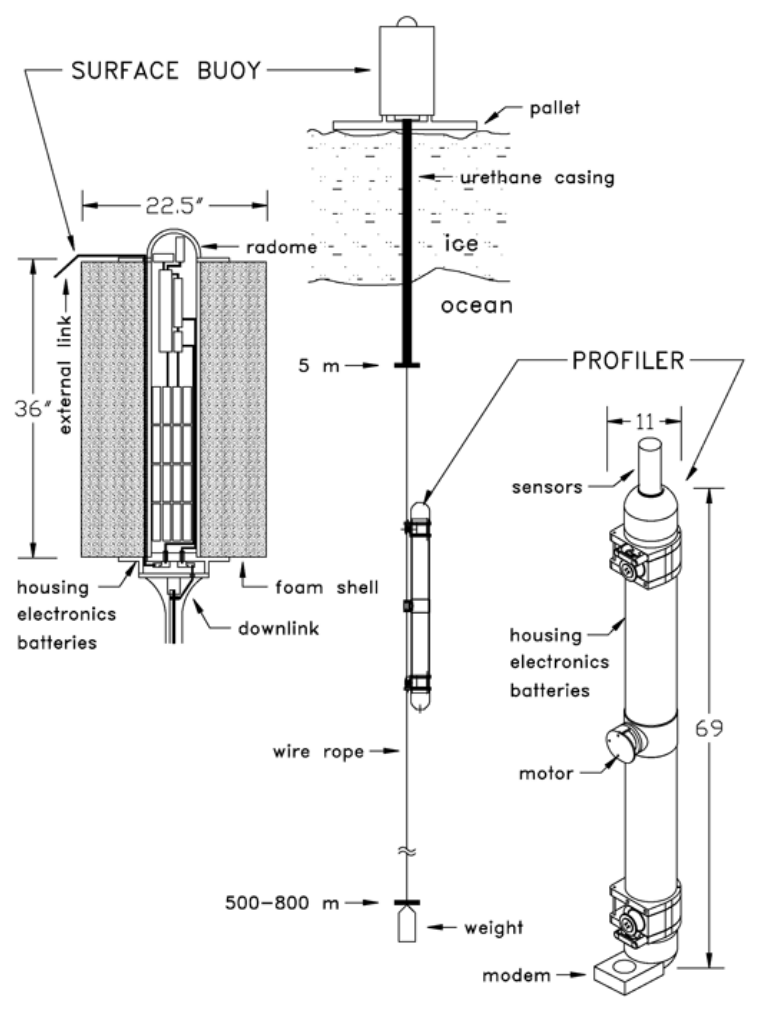

Figure 1. Schematic drawing of ITP mooring instrumentation.

sensor (the Sea Bird Electronics, Inc. model 41CP) that measures the sea water Conductivity, Temperature and Depth at $1 \mathrm{~Hz}$ sample rate. At the design profile speed of $0.25 \mathrm{~m} / \mathrm{s}$, this yields data at a nominal vertical resolution of $25 \mathrm{~cm}$. The full-resolution CTD data, engineering information including drive motor current and battery voltage measurements, and position data (from a GPS receiver in the surface unit) are assembled by a microprocessor computer in the surface unit and relayed to a shore-based computer using the Iridium satellite communications system.

The platform is designed to drift with a supporting ice floe and collect more than 1500 repeated vertical profiles of ocean water properties in the upper $750 \mathrm{~m}$ for up to a 3 year period 
(assuming the supporting ice floe lasts that long). The sampling schedule of the ITP is

programmable, allowing the user to optimally distribute those profiles through time in view of the anticipated ice floe lifetime and space-time characteristics of the upper ocean properties. The data are repeatedly telemetered to shore in near real time for public display and distribution, which can be viewed at http://www.whoi.edu/itp.

\section{DEPLOYMENT APPARATUS}

\section{Winch Mechanical Design:}

The initial requirements for a deployment system for the ITP moorings on multiyear ice floes were constrained as:

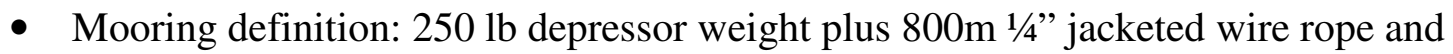
terminated in 5m of 3" OD molded strain relief.

- Deployment system to be un-powered, for payout only

- System to break down for delivery to ice by helicopter sling load or ship's basket/sled

- All parts sized for handling by one or two-persons

- No tools required for assembly (i.e. wrenches)

- 5-ton tripod to be used for support of crown block

The central design challenge was the development of an un-powered payout winch capable of deploying a single mooring which would be pre-wound on a reel. These requirements led to the selection of a winch with a modular mooring reel and a disc-type brake for control of payout. The reel and brake were sized using the spreadsheet shown in Table 1. 
Table 1: Winch calculation spreadsheet.

\begin{tabular}{|c|c|c|c|c|c|}
\hline Depressor weight (air wt) & 250 & \multirow{5}{*}{$\begin{array}{l}\mathrm{lb} \\
\mathrm{lb} / \mathrm{m} \\
\mathrm{m} \\
\mathrm{rpm} \\
\mathrm{min}\end{array}$} & \multirow{5}{*}{\multicolumn{3}{|c|}{ For Constant Torque: $T s^{\star} O D=T e^{\star} I D$}} \\
\hline Wire Wt/m (air wt) & 0.424 & & & & \\
\hline Wire Length & 800 & & & & \\
\hline Drum Speed & 12 & & & & \\
\hline Payout Time & 42 & & & & \\
\hline Drum ID (input) & 12 & \multirow{4}{*}{$\begin{array}{l}\text { in } \\
\text { in } \\
\text { in }\end{array}$} & $\mathrm{OD} / \mathrm{ID}=\mathrm{Te} / \mathrm{Ts}=$ & 2.357 & \\
\hline Drum OD (input) & 28.3 & & Drum OD (calc) & 28.28 & in \\
\hline Wire OD & 0.35 & & & & \\
\hline \multirow[t]{2}{*}{ Packing Efficiency } & 0.8 & & & & \\
\hline & Start & End & & & \\
\hline Tension (wet wt) & 218 & 513 & $\mathrm{lb}$ & & \\
\hline Payout Speed & 0.5 & 0.2 & $\mathrm{~m} / \mathrm{sec}$ & & \\
\hline Torque & 256 & 256 & $\mathrm{ft}-\mathrm{lb}$ & & \\
\hline Power & 0.59 & 0.59 & hp & & \\
\hline \multicolumn{6}{|l|}{ Drum Dimensions } \\
\hline No. Flights & 22 & & & & \\
\hline Avg Dia & 20.15 & in & & & \\
\hline Drum wire $L$ per wrap & 35.4 & $\mathrm{~m}$ & & & \\
\hline No. Wraps & 23 & & & & \\
\hline Width of Drum & 8.1 & in & & & \\
\hline
\end{tabular}

The reel ID was selected as an input and the reel OD was calculated to provide constant torque throughout the payout. The drum width was calculated based on an expected packing efficiency of 0.8, an estimate used for non-level wound wire on drums. A payout drum speed of 12 RPM was selected to provide a maximum wire-out speed of $0.5 \mathrm{~m} / \mathrm{sec}$. The brake was sized based on the calculated payout torque and absorbed power.

Winch design inputs based on the above calculations are summarized below:

- Drum ID: 12 in

- Drum OD: 28.3 in (rounded to 30 in.)

- Torque (constant) $256 \mathrm{ft}-\mathrm{lb}$

- Brake Absorbed Power: 0.59 HP

- Brake Rotor Diameter 24 in (chosen based on Drum OD) 

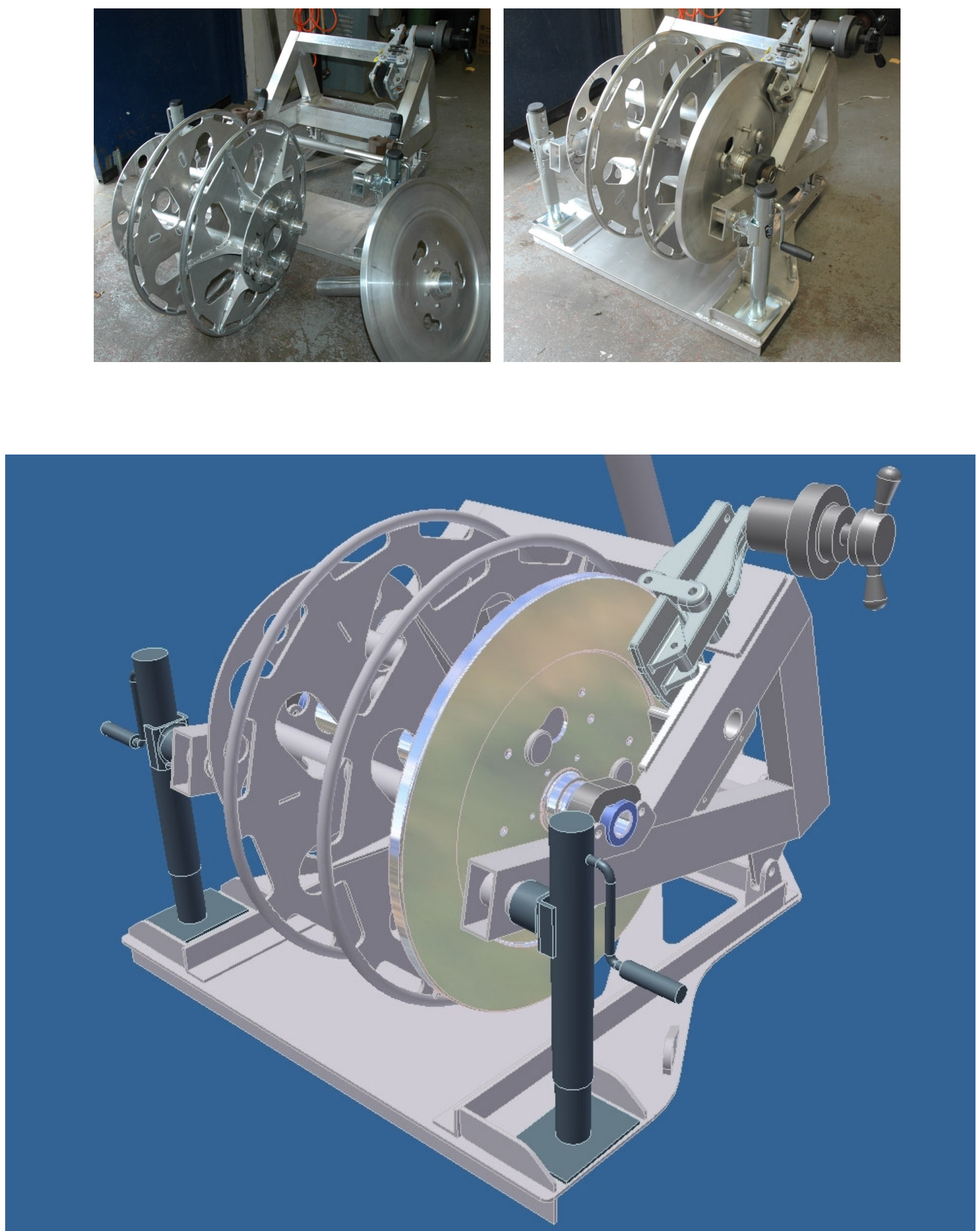

Figure 2. Top: a photo of the winch frame, drum and shaft/rotor disassembled, and a photo showing the system assembled. Bottom: CAD rendering of the winch system. 
SMI Corporation of Douglassville, PA was identified as a supplier of manually-operated brake calipers. Consultations with company sales engineers, along with their online brake calculator tools, led to the selection of the G-Manual Caliper Brake (part number A2936). This brake is normally used in conjunction with a steel rotor, however it was agreed that based on the low-temperature operating environment, the use of an aluminum rotor would be acceptable.

The winch was designed to sit at the base of one of the tripod legs. The bottom (spike foot) of the tripod leg is captured in a pocket at the rear of the winch base plate. In other words, any uplift at the winch is directly balanced by the down force of the tripod leg. The winch base plate has attachment points for chains that run to the other two tripod legs to prevent the legs from spreading. A third chain runs between the other two legs.

In addition, an important frame design input was the requirement to be able to load a full reel, at $480 \mathrm{lb}$, onto the winch in the field. The design chosen uses simple screw jacks to raise and lower the winch frame. This allows the loaded reel to be rolled into place and then lifted off the base plate. The winch frame is raised until the upper member is up against the gantry leg.

The precision required by the brake assembly led to a design where the brake rotor, main winch shaft, and bearings were machined to high tolerances in order to run true, relative to the brake caliper. The reel was designed for a looser fit over the main shaft for field assembly. Studs welded into the drum, engage keyhole slots in the brake rotor, allowing drum torque to be transferred directly to the rotor. Stainless steel quick pins secure the drum in position with the studs engaged. The winch components are pictured disassembled and assembled, and in a CAD rendering, in Figure 2. The overall dimensions of the winch system are shown in Figure 3. 


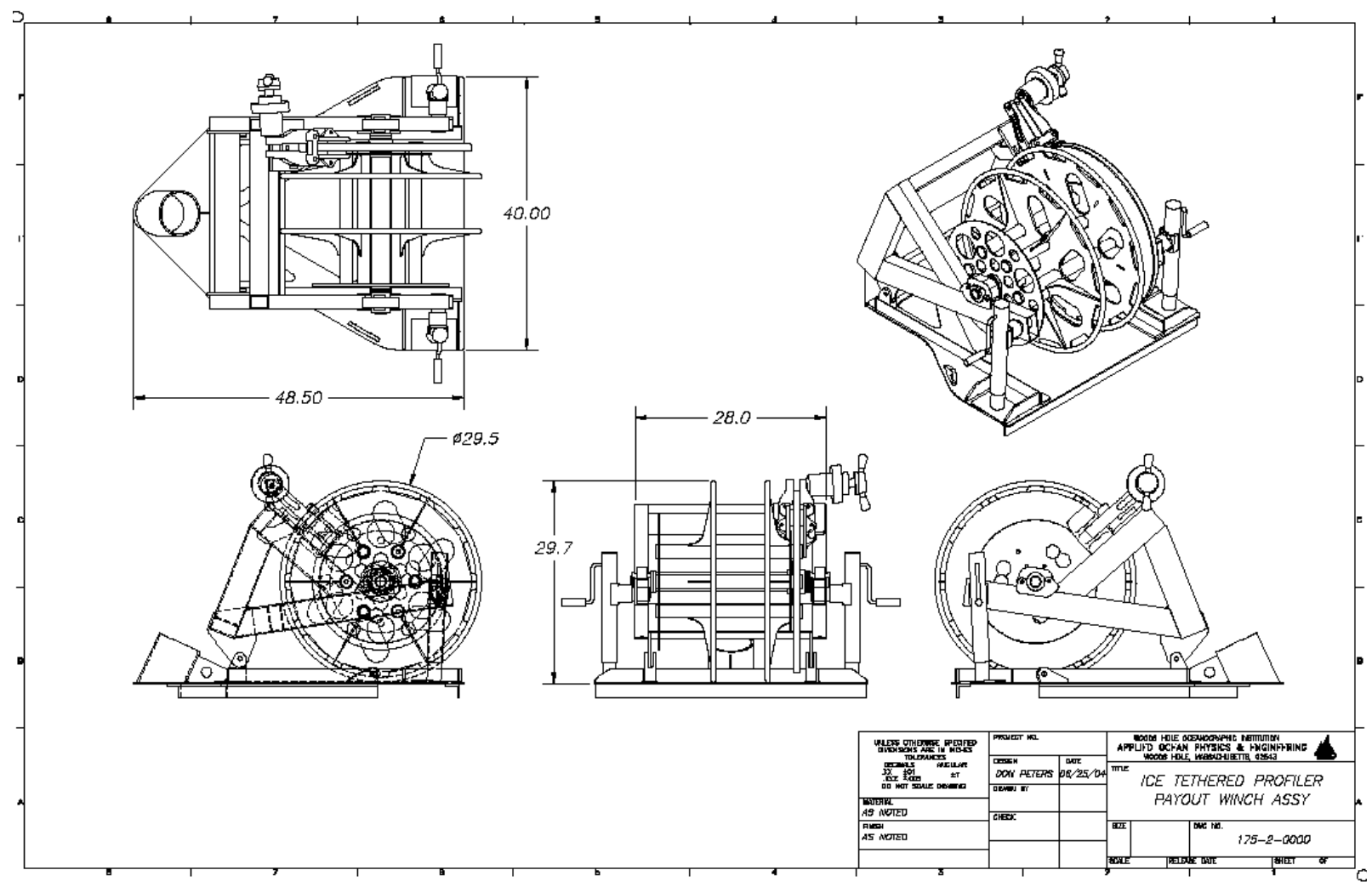

Figure 3. Engineering drawing showing winch overall dimensions.

\section{Handling Gear:}

A limited quantity of handling gear is needed for a deployment operation and does not change when multiple ITPs are being deployed. For simplicity, minimizing what is brought to the ice is a priority. Standard and required items are: a set of 'Lift All' slings, a 'Yale' grip, 6' ladder, 4' and 7' lightweight fiberglass 'Akio' sleds (for moving immobile gear around on the ice), Jiffy Ice Auger components, mechanical and instrument tool kits, and a Honda 3kw generator (if needed for a heat gun/recovery drill). For a complete list of all deployment equipment including the handling gear, refer to Table 2 . 
Table 2: Totals weights for deployment gear

Winch Components

\begin{tabular}{l|l|c} 
& Item & $\begin{array}{c}\text { Weight } \\
\text { (lb.) }\end{array}$ \\
\cline { 2 - 3 } 1 & Empty reel & 49 \\
\cline { 2 - 3 } 2 & Base & 57 \\
\cline { 2 - 3 } 3 & Brake arm & 113 \\
\cline { 2 - 3 } 4 & Rotor disk & 55 \\
\cline { 2 - 3 } 5 & Shaft w/ arbors & 7 \\
\cline { 2 - 3 } 6 & Jack legs & 20 \\
\cline { 2 - 3 } 7 & Recovery drill with extension cord & 35 \\
\cline { 2 - 3 } 8 & Recovery manual handle & 20 \\
\cline { 2 - 3 } & Assembled Winch Total & 356 \\
\hline
\end{tabular}

Tripod Components

Auger Components

\begin{tabular}{l|l|c}
\cline { 2 - 3 } 1 & Tripod (3 legs), spider, shackle clevis & 127 \\
\cline { 2 - 3 } 2 & $6 "$ 'McKissik' snatch block & 28 \\
\cline { 2 - 3 } 3 & Ross' chain hoist & 25 \\
\cline { 2 - 3 } 4 & Aluminum cleat with 1/2" hardware & 7 \\
\cline { 2 - 3 } 5 & 6 ' Step ladder & 25 \\
\cline { 2 - 3 } 6 & Ice tools: shovels, picks, chisels, extension cord & 30 \\
\cline { 2 - 3 } 7 & $100 '$ VLS & 252
\end{tabular}

\begin{tabular}{|c|c|c|}
\hline \multicolumn{3}{|l|}{$u_{y}$} \\
\hline & 10" Auger flights (5) in bag w/ 11" extension & 70 \\
\hline & 2" Auger Flights (5) in Case w/ Handle & 32 \\
\hline & Jiffy Head \#1 in bag & 30 \\
\hline & Jiffy Head \#2 in bag & 30 \\
\hline \multirow[t]{2}{*}{ sal } & Jiffy head parts kit box w/ oil etc. & 10 \\
\hline & Auger Component Total & 172 \\
\hline \multicolumn{3}{|l|}{ Assorted Handling Gear } \\
\hline & Standard 2 each orange ITP tool kits & 57 \\
\hline & Milk crate: 'Yale Grip', slings, winch spares, tripod chain, etc. & 60 \\
\hline & Akio' sled (7') \& 'Akio' sled (4') & 39 \\
\hline & Honda $3 \mathrm{Kw}$ generator in arctic field box & 204 \\
\hline & Handling Gear Total & 360 \\
\hline
\end{tabular}

ITP Components

\begin{tabular}{l|l|c}
\cline { 2 - 3 } 1 & Ice-Tethered Profiler instrument in box & 150 \\
\cline { 2 - 3 } 2 & ITP assorted tools/spares in kit & 10 \\
\cline { 2 - 3 } 3 & ITP Surlyn buoy with batteries & 138 \\
\cline { 2 - 3 } 4 & ITP buoy plywood (box) & 100 \\
\cline { 2 - 3 } 5 & Wire rope mooring tether & 431 \\
\cline { 2 - 3 } 6 & ITP Assembled anchor, 4 ea. 1/2" Shackles, 2 ea. 5/8" Sling links & $\mathbf{1 0 8 5}$ \\
\cline { 2 - 3 } & ITP Component Total & $\mathbf{2 2 2 5}$
\end{tabular}




\section{PRE DEPLOYMENT OPERATIONS}

Before surveying the deployment site, the instruments and deployment gear should be prepared for transport to the deployment site for rapid installation. The surface package and instrument may be attended to several days or more before arriving at the intended site. The procedures for the pre-deployment preparations of the instrumentation are as follows:

Syntactic Surface Package Preparations:

The ITP surface float is shipped assembled in a wooden box and with the lithium batteries installed, but unplugged. The sides of the box are used after the deployment to make a palette under the deployed buoy. Days before, the electronics package should be removed, the batteries plugged in, and the pressure case reassembled, to start the surface controller operation. If time permits, the surface package should be set up outside so that the GPS and Iridium transmissions can be verified for several days or more before the deployment.

\section{Ice Tethered Profiler Preparations:}

The battery of the ITP profiler is also usually shipped with the battery unplugged in the sealed anodized aluminum pressure tube. After the battery is connected and the instrument reassembled, it can be programmed from an external port - either in a tent or on a ship before the deployment, or it can even be reconfigured on the ice, if the weather permits. It is recommended that the ITP profiler be configured to begin within several hours after the anticipated deployment conclusion. The instrument should be kept in temperatures above the freezing point prior to deployment as operation of the electronics is not guaranteed at colder temperatures. 


\section{Deployment Apparatus Preparations:}

The steps involved with assembling the deployment apparatus for transport depend upon whether a helicopter is used to get the gear to the deployment site. If a helicopter is available, then care has to be taken to minimize the amount of gear needed to be transported. However, if the site is only accessible by the over-the-side method (by way of the ship's basket or gangplank), the quantity of gear is less a factor, but still should be considered.

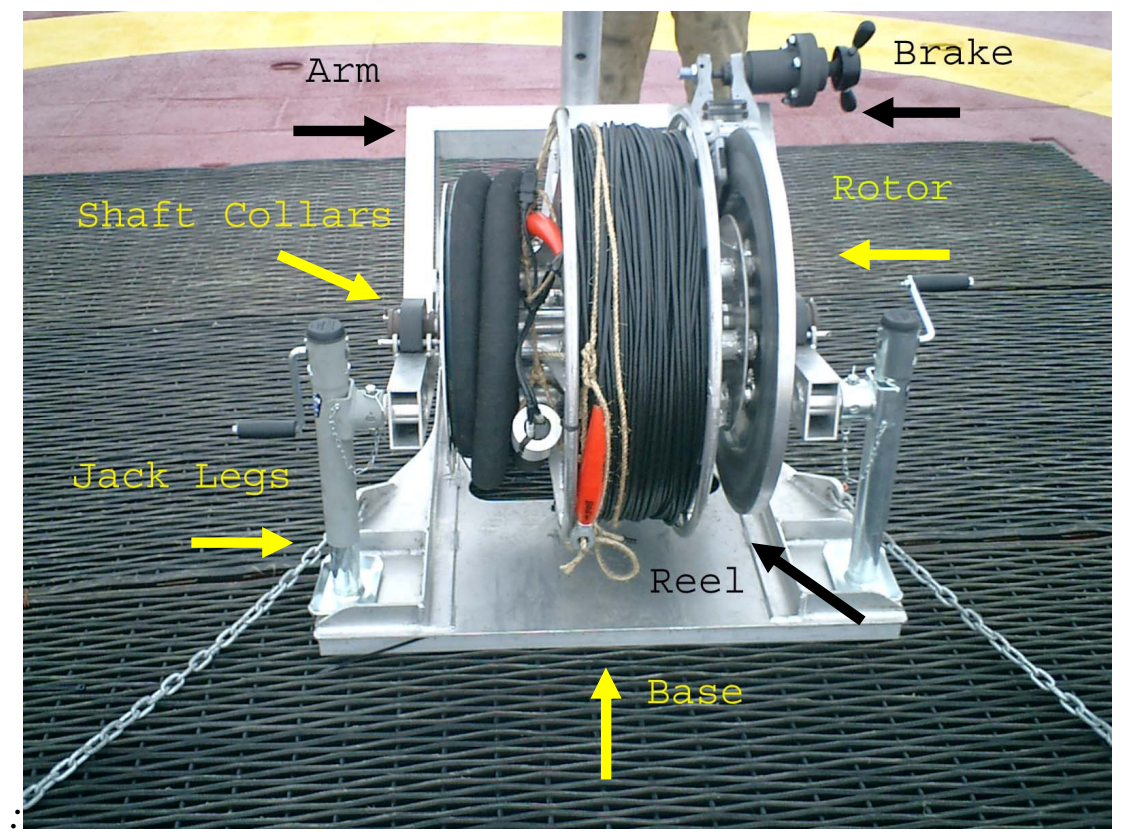

Figure 4: Winch system components with ITP tether preloaded.

\section{The Winch Assembly:}

The ITP winch was designed as a light weight winch system that is able to be assembled and disassembled very quickly and easily, either on deck or on the ice, thus requiring only one person, but preferably using two. It must be noted that on a typical cruise aboard a vessel, the 
winch is shipped assembled; however time is spent here to discuss overall assembly procedures in case they're needed. Refer to Figure 4 for the names used to identify the parts of the winch.

The assembly of the winch should commence at the exact location where it will be slung to the ice because once assembled, it will be difficult to move around. The winch comprises of six sets of pieces: the base, brake arm, two support jack legs, the reel with wire, shaft with arbors, and the brake rotor. The procedures for the complete assembly are as follows:

a. The base of the winch should be placed on a flat and sturdy platform.

b. The brake rotor is slid through the reel and rotated to lock into the reel's locking hubs. Three SS quick release pins make the reel and brake rotor secure.

c. The shaft is then inserted through the brake rotor and reel. Place two arbors on the shaft at each end, thus creating one assembled unit. Note: With the weight of the brake rotor off to one side, the reel becomes unbalanced so care should be taken to keep the reel upright and steady.

d. Roll the reel onto the base making sure the brake rotor slides between the two brake pads (the brake must be loosened). In order for the reel assembly to lock into place, you must lift the brake arm to assist the brake rotor between the pads. Also, the arbors on either side of the reel need to be positioned so they roll into the sleeve color.

e. Place the Delrin shaft sleeve colors over both arbors and lock into place using four SS quick release pins.

f. Position the two jack legs on either side of the brake arm and lock into place using the two pin assemblies.

g. Jack the two legs up until they are both even. Do not jack the reel off the base. 
The winch and other components are now completely assembled and prepared for a deployment procedure. However for flight operations, a 20' 'Lift All' ratchet strap is wrapped completely around the winch (and underneath the base) and tightened to keep the wire and corresponding winch segments secure. A canvas wrap is placed on the wire to reduce the risk of abrasion throughout the transport process. A six foot 'Lift All' sling is chocked around the arm of the winch adjacent to the brake. The selected spot is important in keeping the winch balanced throughout the flight and to reduce spinning. The anchor is then slung to the ice. The process up to this point, on average, takes 30 minutes.

Table 3: Itemized ITP deployment parts list

\section{Tripod Components}
a. 3 each tripod legs with insert pins
b. 3 each feet inserts (two have galvanized eye nuts attached)
c. 3 each chain legs (5/16" galvanized chain and 5/16" screw pin shackles)
d. Spider with 3 pins
e. Top clevis with 3 each 5/8" sling links and 3 each 5/8" screw pin shackles
f. $1 / 2$ Ton chain hoist (Ross)
g. McKissik 6" snatch block
h. Cleat with 2 each $1 / 2$ " x 5" bolts, lock washers, flat washers, and nuts

\section{ITP Deployment Winch Components}
a. Aluminum reel with $790 \mathrm{~m}$ of $1 / 4$ " wire \& molded chain (with Delrin inserts)
b. Brake/base assembly
c. Insert quick release pins (+ spares)
d. 2 each lifting legs
e. $250 \mathrm{lb}$. anchor
f. Shaft
g. 4 each shaft arbors
h. Recovery handle

3. Motor Powered Ice Auger (10") - Ice Accessories
a. 5 each $1 \mathrm{~m}$ flight extensions
b. 1 each 11 " flight extension
c. Cutting blades (spares in bag)
d. Jiffy Head (1-spare if needed)
e. 2 cycle gas mixture 
f. Chisel and ice scooper ('Chipper Dipper')

g. Ice Pick(s)

h. Shovel(s)

4. Hand Powered Ice Auger (2")
a. 5 each flight extensions
b. 2" cutting bit (+1 spare)
c. Handle assembly
d. Carrying case

5. Akio Ice Sleds: Small 4' and Large 7'

6. Handling Gear and General Supplies (orange tool boxes-milk crates)

a. $88 / 23$ tape (2-3 each)

b. 2 each 4' slings; 2 each 6' slings; 2 each 8' slings

c. Tie wraps (8")

d. 2 each $1 / 2$ " safety shackles with cotter pins

e. 5/8" sling link (wire to anchor connection)

f. Black rope knives

g. 100' VLS (slip line)

h. 2 each 10 " 'Crescent' wrenches

i. 2 each angled cutters

j. 2 each $1 / 2$ " x 5 1/2" SS HH bolts, lock washers, flat washers, nuts, and bolt bushings

k. 3/8" drive socket set

1. 2 each $3 / 4$ " box wrenches

m. 7/16", 1/2", 9/16", and 3/4" box wrenches

n. Cotter pins

o. 2 each 'Yale' grips

p. Cordless drill (spare charged battery)

q. Blue grease (with acid brushes)

r. 6' ladder

s. Ice thickness gage and ice floe detection device (steel)

t. 4 each large pieces of plywood (removed from ITP buoy box)

7. Instrument and Electronic Supplies (grey tool box)
a. 88 tape
b. Tie wraps ( 8 ")
c. Utility knife
d. 2 each 8" 'Crescent' wrenches
e. Angled cutters
f. Needlenose and 8" pliers
g. Small slotted, regular slotted, and phillips screwdrivers
h. 3/16" long shaft ball driver
i. $3 / 32$ ", $1 / 4$ ", 5/32", 5/16", 7/64", 9/64" and 3/8" ball drivers
j. $3 / 8$ ", 7/16" and 11/16" box wrenches
k. 1/2-13 x 3" Nylon SH bolts 
1. Spare SS SH bolts, washers, locks

m. Spare snap ring, \#4\&6 plugs

n. Spare O-rings (\#163 profiler, \#238 drive motor, \#254 piston, \#259 dome)

o. Desiccant packs

p. Heat packs

q. Cotton swabs

r. Wipes

s. DC-4 grease

\section{Surface Package and Profiler Components}
a. Surlyn Foam Buoy
b. Ice Tethered Profiling Instrument
c. 2 - ITP bumper stops
d. Boat gaffe

\section{Generator and accessories (only needed for recovery of ITPs)}
a. Honda $3 \mathrm{kw}$ generator in arctic field box
b. Heat gun
c. Motorized recovery drill
d. 24" hot water drill ring and apparatus

Deployment Site Selection, Survey, and Analysis

Before ITP installation can begin, the first task is to pick potential multiyear ice floes and try to select ones that could support a profiler for several consecutive years. From an ice breaker, a few different methods may be relied upon to find floes in the relative area $(<60$ nautical miles from the ship). One method entails making observations from the ship by looking overboard while transecting through the ice. There can always be multi-year ice in and amongst single year ice that could potentially suit our needs. Another method relies on determining ice quantity and thickness based upon satellite imagery of the area(s) of interest. Operational images may be updated every few days which gives the team a real time look at current ice conditions. By examining the colorization and referencing operational ice forecasts, the ice observer has a preliminary look at potential deployment sites from afar. 


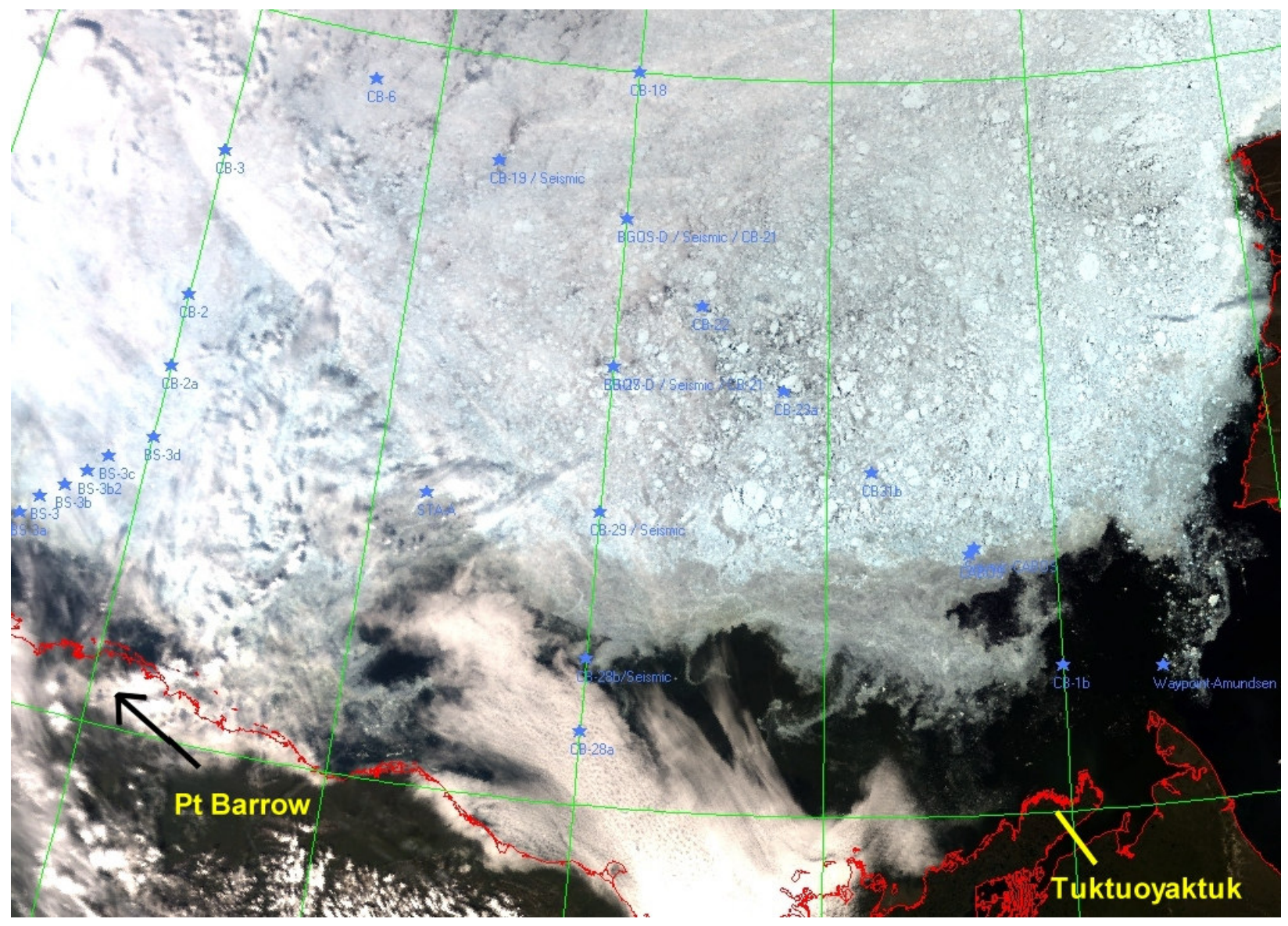

Figure 5: MODIS satellite imagery of ice concentrations and locations in the Beaufort Sea

If a helicopter is available, and at least two to three sites have been chosen and are within distance (depending on fuel and visibility constraints), an ice observer (if available), 1-2 field technicians, and the pilot should make a reconnaissance flight. The ice observer gives the locations of potential deployment sites to the pilot who in turn plots courses using the helicopter's onboard GPS flight system. To survey the thickness of a suitable floe, a 2" hand auger (5 lengths each 1m long), a 4' 'Akio' sled, an ice thickness measuring device, and site marker flags should be packed in the cargo bay of the helicopter. 


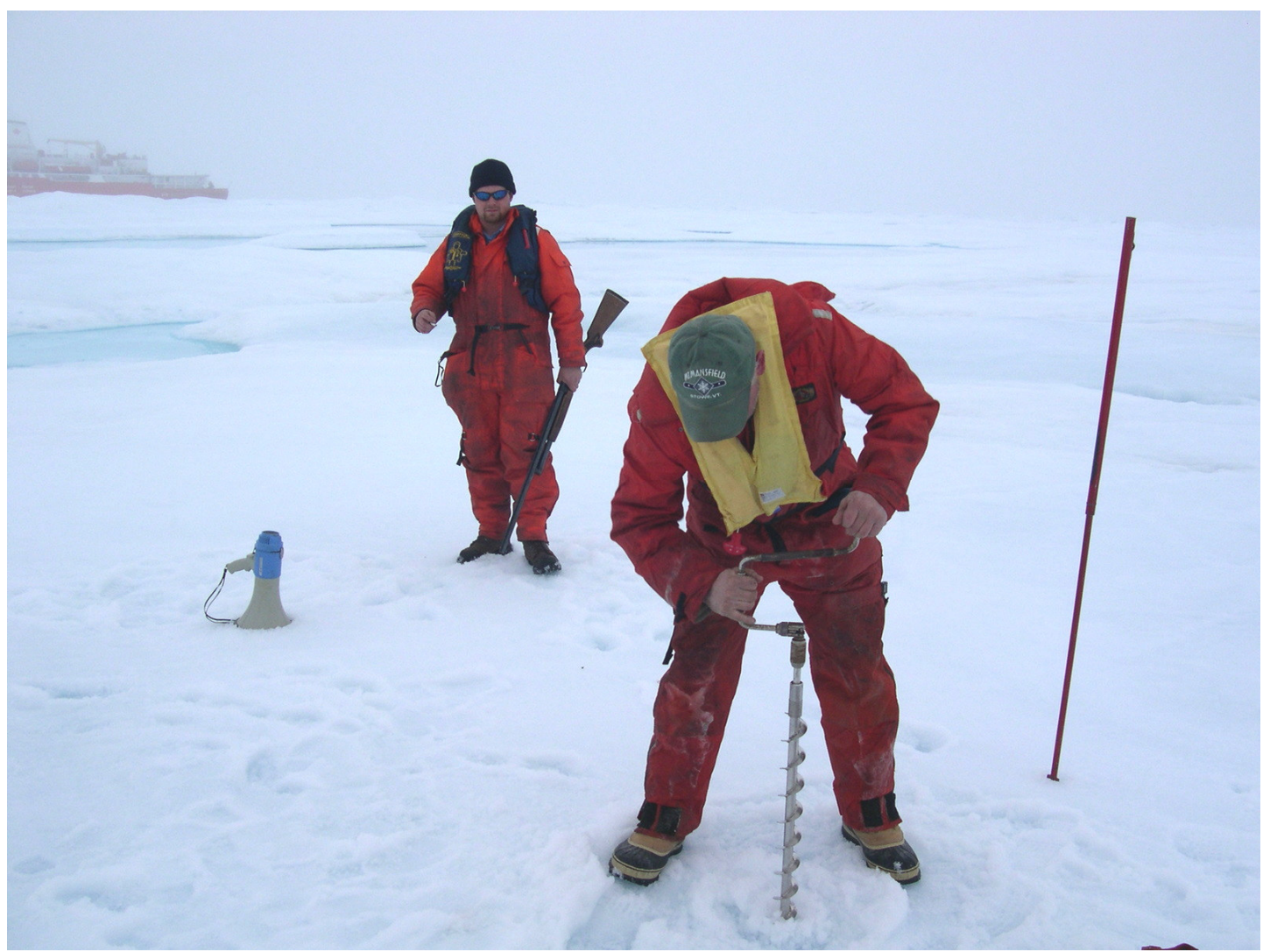

Figure 6: With armed protection, the 2" hole is drilled during the ice survey

Once the first site has been found from the air, a quick visual survey is performed from roughly 200' in every direction. There is a specific set of criteria used in order to determine if the site is suitable before landing, including, but not limited to: a relatively light blue color of ice which indicates multi-year thickness; a set of medium height ice ridges surrounding the site which acts as a barrier (no ridges in the middle); and few cracks anywhere on the floe which could be a sign that the site is already broken up by colliding and rafting floes. Furthermore, the ultimate goal is find the best piece of ice possible within the available time (which can vary). Once the decision has been made to test the site, the helicopter lands adjacent to the potential spot where the deployment hole will be drilled. Using the 2" hand auger, multiple test holes are drilled then measured to determine ice thickness. 
Generally, any piece of ice that is thicker than 2.5 meters and less than 4.5 meters, and is not located in (or too near) a ridge, is considered acceptable. The best ice is hard low salinity multiyear ice that grew uniformly over a number of years without internal cracking and with wide ridge spacing. In these cases, the ice thickness measurements vary little throughout the floe. If there are large variations in ice thickness in the floe, then turbulence below the ice will ablate the floe unevenly which could lead to mechanical failures. In some instances, ice as thin as $1.5 \mathrm{~m}$ may have to be considered, but with the understanding that the probability of longevity of the deployed ITP system is reduced.

In addition to the thickness, the quality of ice that is being drilled needs to be considered. In other words, from a standing vantage point, the ice may seem thick and hard enough to work with, however once the drilling begins, porous and unacceptable ice may be found. If this is the

case, finding another floe may be the only option. If the site is acceptable, flags or other kinds of markers are set up to establish the camp which must be able to be visible from the ship.

If a helicopter is not available, then the same ice thickness measuring operations can be employed by lowering the personnel and equipment over the side of the ship while secured (or pushed against) an appropriate ice floe. For safety concerns, this would typically limit range to a deployment site to within a few hundred meters in summer, before leads or melt ponds create logistical problems.

\section{DEPLOYMENT OPERATIONS}

Once the deployment site has been chosen, then the decision has to be made to begin deployment operations. The amount of time that will be required for transporting everything (Table 3) to and from the selected site will depend on distance from the ship. Poor weather 
conditions can also lengthen the deployment operation. Under the best conditions, using a helicopter on a nearby site $(<200 \mathrm{~m})$, the complete operation to deploy an ITP can take less than 3 hours, however it is more reasonable to budget 6 hours for a deployment to account for any difficulties (these times do not include the time for ice reconnaissance and survey, which can become very long in poor ice conditions). When a 4-6 hour period in the foreseeable future can be dedicated to the ITP field operations, the deployment can begin. Immediately, a check list should be made in order to make sure that all gear is accounted for and staged for transport to the deployment site.

\section{Transportation of ITP and Deployment Gear to Site}

When using the BO-105 helicopter, the total number of trips of personnel and gear has typically been 8 , plus return flights after deployment operations. Staging the gear in the helicopter hangar prior to the first flight is a necessity for both reducing the chance of forgetting equipment, and for keeping the process moving as quickly and efficiently as possible. In the operations performed to the present, the first two flights to the ITP site are always personnel flights, bringing to the ice a total of two WHOI team members (the third stays on board to oversee the loading process) and three ship crew members. Two of the crew members are there to assist with unloading the helicopter cargo hold and managing the gear being slung. The third crew member's responsibility is to provide a polar bear watch, carrying with him a rifle for protection. During the first two flights, no gear is slung by the helicopter. However, gear can and should be transported to the ice using the cargo hold area in the back to optimize efficiency. It should contain handling gear (refer to the itemized deployment list), Jiffy auger and accessories, tripod components, and Akio sleds. 
The third and fourth flights contain no personnel, but rather are used to sling the ITP winch and the $250 \mathrm{lb}$. preassembled anchor or depressor weight. The winch is completely assembled and has the reel with $790 \mathrm{~m}$ of $1 / 4$ " wire rope locked into place by the shaft, arbors, and a ratchet strap.

The fifth, sixth, and seventh flights consist of bringing the remaining team members and any additional gear and personnel that has yet to be brought to the ice. It is very important to note that two very important pieces of equipment, the surface package and profiler, have yet to be brought to the ice, but instead, located in the helicopter hangar and not on the ice exposed to the elements. Both pieces of equipment are brought to the ice only when it is time for the deployment process to begin.

\section{Drilling Operations and Tripod Setup}

Once the deployment and handling gear is on the ice, assembly of the tripod and drilling the deployment hole can begin. Regardless of the ice's thickness, the tripod is the first piece of gear to be assembled. In order to fit the tripod in the helicopter during flight operations, it may need to be taken apart into three sections, all of which are easily disassembled and reassembled by using quick release pins (this certainly depends on the size of the helicopter). Once the tripod is fully extended and upright on the ice, the clevis and $1 / 2$ ton chain fall are hung in the apex using the 6' ladder. The tripod is used before the deployment operations take place in order to support the weight of the auger when multiple one meter flight sections are attached when drilling. Drilling using the first flight can and should be done by hand, without the assistance of the tripod and chain fall, however as more and more flights are added because of ice thickness, attaching two slings to the handle of the auger and linking them to the chain fall's hook makes the process 
of drilling the hole easier, safer and faster. (Note: the use of an 11" inch cutting bit with 10" flights causes the process described above). Care has to be taken when assisting the auger with the chain fall. In order to reduce the auger from stalling and keeping the hole free of snow and ice, it is essential for the chain fall tender to carefully ease the auger up and down slowly to optimize drilling performance.

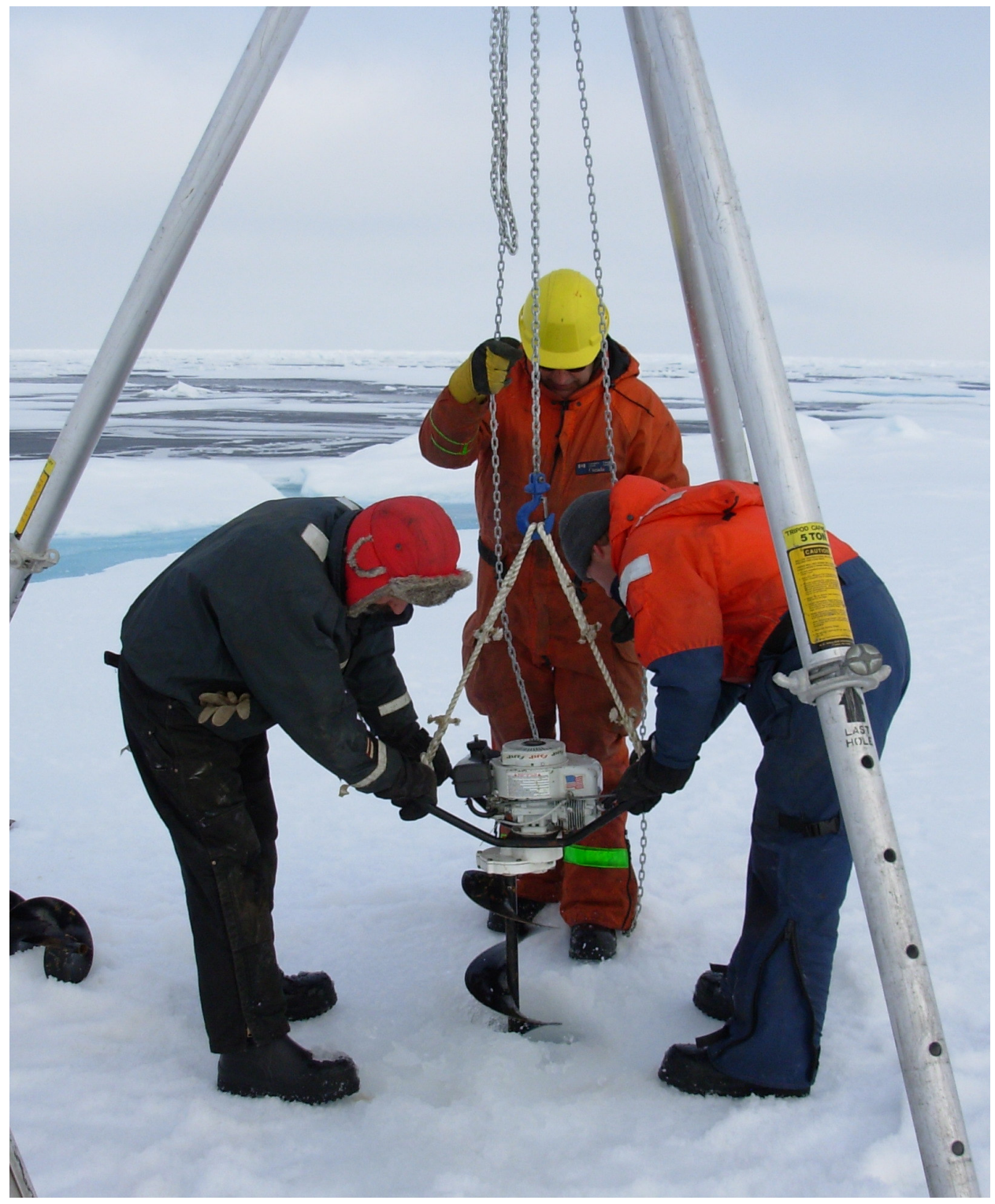

Figure 7: Drilling operations using the tripod and chain hoist for assistance. 
When a large volume of sea water finally gushes from the hole, it is an indication that the hole is completely through the floe. However, in order to be completely sure, a survey device (weight on a rope) should be lowered down through the drilled ice hole to at least an additional two to three meters below the bottom of the ice floe ( 8 to $9 \mathrm{~m}$ from ice surface). This will ensure that there are no false bottoms or floes that may have rafted underneath. Once the determination has been made that the hole is clear, a piece of plywood should be placed over the opening for safety and also to keep snow and ice from entering it. Drilling operations are finished and further assembly of the deployment apparatus can commence.

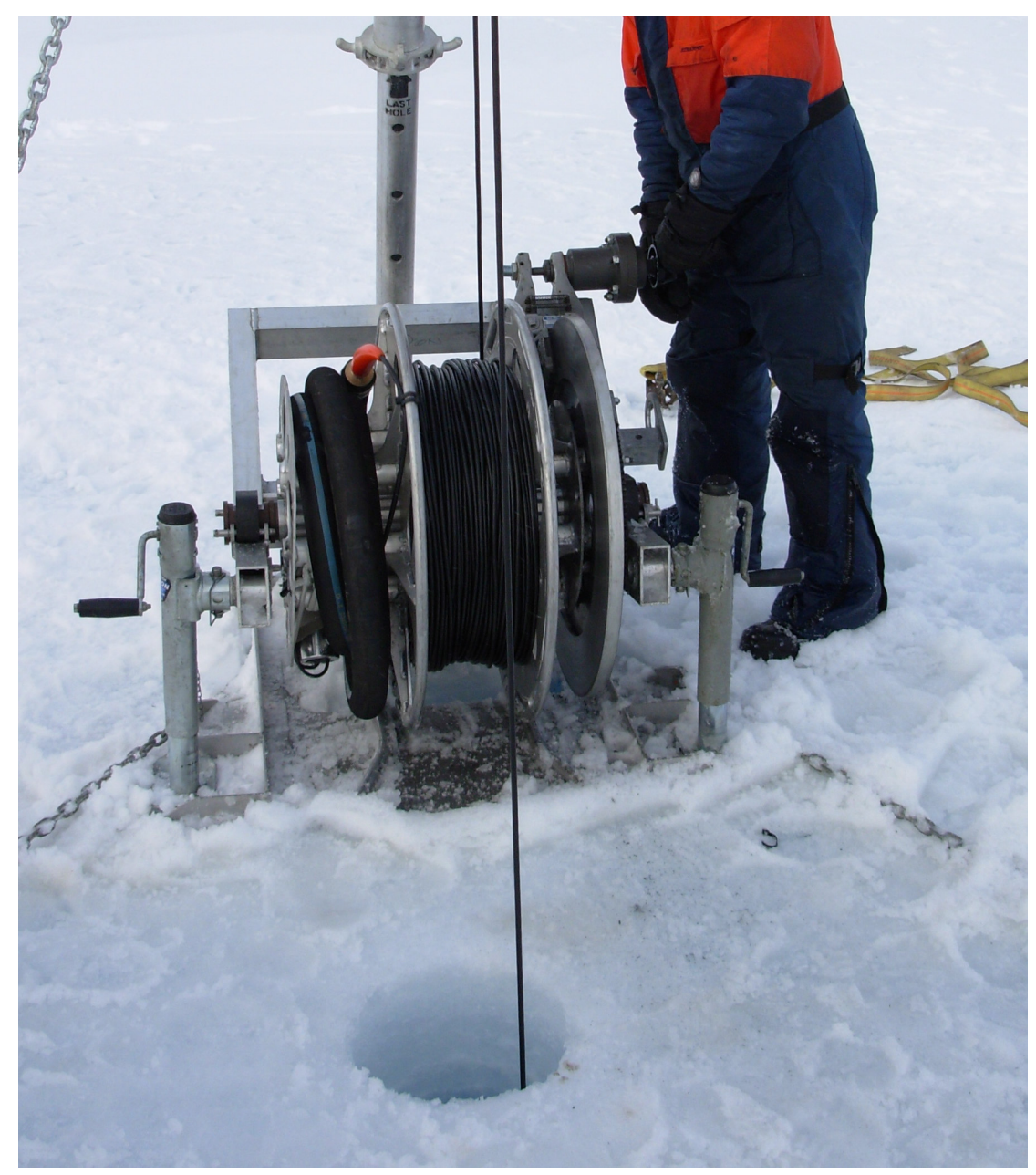

Figure 8: Correct positioning of the winch and brake operator in relation to the deployment hole. 


\section{Winch Operation and Placement}

With the deployment hole drilled and the tripod already setup in place directly over the hole, the ratchet strap and sling should be taken off the ITP winch. The winch should have been previously assembled on the ship, so no adjustments should need to be made in the field. Also, a call should be made to the ship to have the surface package and ITP brought to the ice. When the two pieces arrive, care should be taken to place them away from the assembly area in order to insure their safety. The profiler instrument should be kept in the box as long as possible in order to protect it from the elements.

At this point, the 6" McKissik snatch block can be hung in the middle of the top clevis (apex of the tripod), adjacent to the $1 / 2$ ton chain hoist which is off to one side and clipped into a 5/8" pear ring. Also, the aluminum cleat should be bolted to the side of the tripod using 2 each $1 / 2$ " SS hex bolts. Using the 4' 'Akio' sled, the winch is brought to the deployment site and placed roughly 12" from the hole. It is important to note that the winch needs to be placed on a flat ice surface to operate properly on deployment. If difficulties are met with positioning the winch because of the weight, the winch can and should be taken out of its locked position and rolled clear of the area until the winch is placed correctly in relation to the hole. Once in place, the reel is rolled back into position and locked into place.

Place one tripod leg (without the galvanized eye nuts) through the back of the winch base. Attach two 5/16" pre-cut galvanized chain segments from the other two legs to the winch base with 5/16" screw pin shackles. Attach the third galvanized chain segment (longest of the three) to the two remaining legs and pull all of the chain segments tight. This process is important to locate the winch and the tripod so the center of gravity is directly over the hole and below the apex of the tripod. This can be tested by running the $1 / 4$ " wire rope up through the block hung 
directly over the hole. When hand tension is applied, the wire should be near the center of the hole, but slightly off to one side which will ease the ITP instrument passage through the hole. If this is not the case, then time should be taken to move the winch and corresponding tripod legs until centered.

Table 4: ITP deployment tensions

\begin{tabular}{|c|c|c|c|c|}
\hline $\begin{array}{l}\text { Units } \\
\text { (ea) }\end{array}$ & $\begin{array}{l}\text { Mooring Component } \\
\text { Description }\end{array}$ & $\begin{array}{c}\text { Stretch } \\
\text { Length } \\
\text { (M) }\end{array}$ & $\begin{array}{l}\text { Total } \\
\text { Ww } \\
\text { (Lbs.) }\end{array}$ & $\begin{array}{c}\text { Anchor } \\
\text { Tension } \\
\text { (Lbs.) }\end{array}$ \\
\hline 1 & 33" - Syntactic Surface Package & & & \\
\hline 5 & 5 Meters 1/4" Wirerope Strength Member w/ coil cord & 4.8 & -14.5 & -477 \\
\hline 790 & 790 Meters 1/4" Jac.Nil. Wirerope & 790.0 & -210.0 & -462 \\
\hline 1 & Hardware & 0.2 & -2.6 & -252 \\
\hline 1 & 250 Lb. Ww Anchor & 0.7 & -250.0 & -250 \\
\hline \multicolumn{2}{|r|}{ OVERALL ITP MOORING LENGTH } & 795.7 & & \\
\hline
\end{tabular}

\section{ITP Installation}

Place the assembled anchor on top of the plywood directly over the hole and insert the recovery handle in the right side of the winch. Take two each $1 / 2$ " anchor shackles and one each $5 / 8$ " pear ring and make the wire swage - anchor termination connection and insert cotter pins. Place and tighten the ITP bottom bumper stop on the wire approximately 1 meter from the termination, making sure this accommodates the programmed instrument depths.

Placement of the deployment personnel at the beginning of the deployment is critical to ensure a safe and efficient deployment procedure:

a. One team member should stand next to the winch brake and is responsible for controlling the wire pay out speed and stopping when necessary.

b. A second team member should stand by to control the chain hoist when needed 
c. A third team member is accountable for the ITP instrument and places it on the wire rope. This may take 2-3 additional team members to make certain the instrument isn't damaged and the collars around the wire are tightened.

d. As the deployment procedure nears the end, team members need to handle the slip line, stopper, and make mechanical and electrical connections.

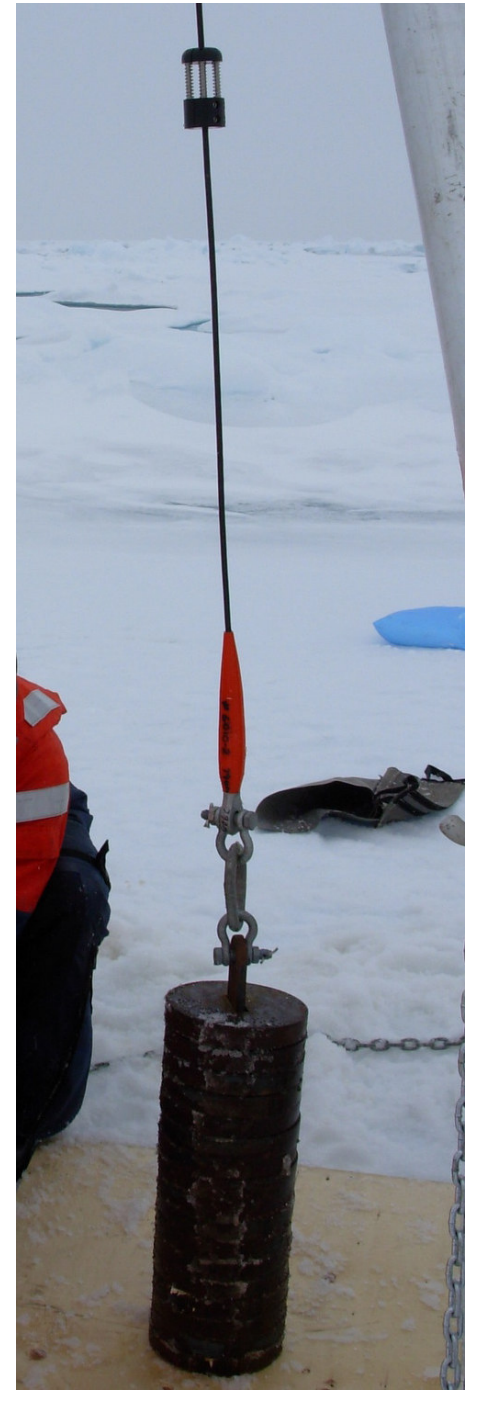

Figure 9: Anchor connection on wire and correct bumper placement.

Once the team is positioned and ready, the anchor is lifted off the ice using the recovery handle and the brake tightened, suspending the anchor 1' above the hole. The plywood is removed and the instrument taken out of its protective box and brought close to the hole. Loosen the brake and allow approximately ten meters of wire to pay out. Tighten the brake, thus stopping the mooring.

The profiler instrument's guiding collars, inductive modem collar, and sensor caps need to be removed so it can be placed on the $1 / 4$ " wire rope. Using the $3 / 8$ " VLS line, fix a clove hitch to the instrument below the top collar, then feed the line through the $5 / 8$ " pear ring which is shackled into the tripod clevis. Take up the slack and tie off to the cleat bolted to the leg of the tripod, consequently suspending the instrument safely above the deployment hole so reattachment of the collars can occur (being careful not to lose the magnet in the inductive modem collar). Once the instrument pieces are tightened and secure, a team member 
can hoist the instrument so as to take the load off of the VLS line. The line is then removed and cleared from the tripod clevis.

The instrument is then slowly and very carefully pushed down the deployment hole, making sure the different sensors are clear from the ice on either side of the hole. (Note: It may take a few minutes for the instrument to ballast itself and slowly sink). The instrument can also be assisted down the hole with the wooden end of a shovel or similar tool, but care must be used to avoid the sensors (push cable guide surrounding wire). Once satisfied that the ITP has cleared the ice, the deployment of the wire can continue. It is important that once the brake is loosened the operator's hands should stay on the brake handle so that the mooring cable does not pay out too quickly. The wire has a tendency to change speeds periodically during deployment because of break pad resistance so care should be taken to control the speed at all times.

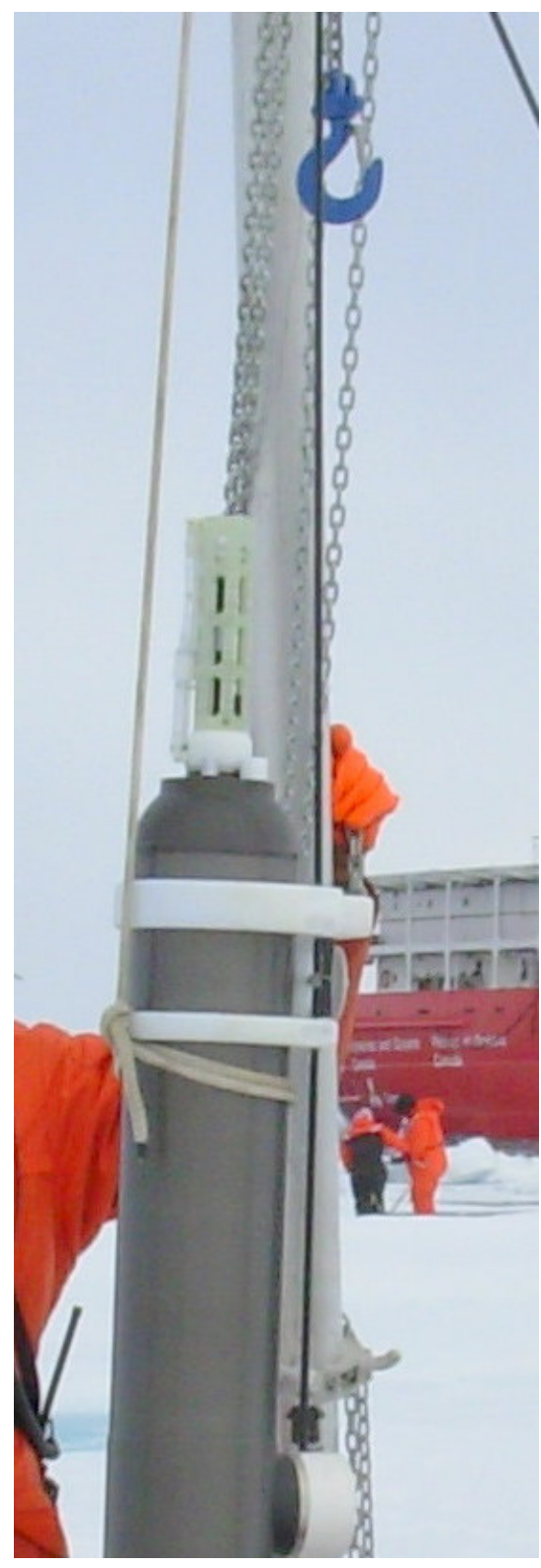

Figure 10: Clove hitch placement for supporting the ITP on the wire rope.

\section{Stopping Off:}

When approximately $780 \mathrm{~m}$ of wire has been deployed (roughly 1 layer of wire left on the width of the reel), the brake is tightly applied and the mooring stopped. At this point, the anchor and cable impart a $460 \mathrm{lb}$ load on the mooring wire (Table 4) which must be transferred 
from the winch to the surface buoy. Care must be taken throughout this procedure to ensure that the weight of the mooring system is under control at all times while the mooring wire and potted segment is unwound from the winch and attached to the buoy.

Using a 'Yale Grip' or a similarly rated product, carefully braid then tape the stopper line to the $1 / 4$ " wire rope (see Kemp et al., 2005). Make sure that the full braid is used when applying the 'Yale Grip'. Clip the $1 \frac{1}{2}$ ton chain hoist hook into the eye of the 'Yale Grip' and take strain, hence taking the load of the mooring (Note: carefully watch the wire rope to make sure it doesn't slip - if done correctly, the grip will safely and securely hold the mooring in place so work can continue).

Once the mooring is stopped off, all team members should assist in removing the remaining wire and potted strength member remaining on the reel. Also, someone must climb the 6' ladder to remove the 1/4" wire from the snatch block. Walk the cable away from the winch and place it on the ice making sure there are no kinks in the segment.

Away from the tripod adjacent to the molded chain's top fitting, the syntactic surface package is then placed on its side and its bottom clevis removed thus revealing the electrical wires within. Carefully unite the electrical connections from both, the molded chain and the surface package, making sure the connection is sound and watertight, and fasten locking bands. Bolt the bottom clevis back on to the bottom plate of the surface package. Make sure there are 2 each Delrin $1 / 2$ " sleeve bushings already in place through the aluminum fitting of the coil cord strength member for isolation purposes. Using 2 each 1/2" x 5 1/2" SS hex bolts, flat washers, Delrin bolt bushings, and lock washers, bolt the molded chain to the bottom clevis making the mechanical connection of the ITP mooring. 


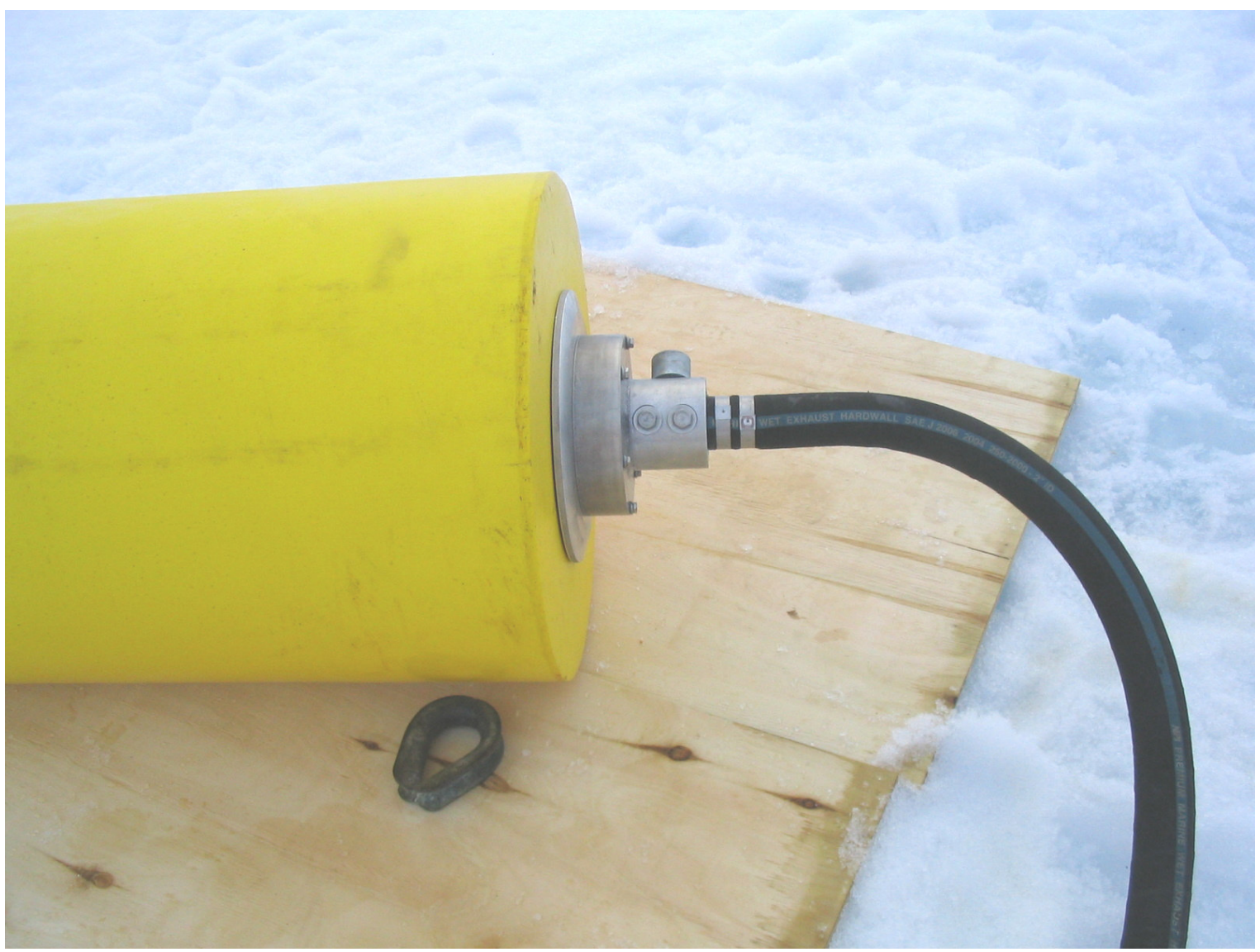

Figure 11: Mechanical connection between the strength member and surface package

\section{Slipping Positions and Procedures:}

In order to lower or slip the remaining wire, potted coil cord strength member, and surface package over the deployment hole, first remove the $1 / 2$ " tygon tubing that has been preattached and taped to the $1 / 4$ " wire rope. Attach the SS slip bale to the $1 / 4$ " wire just below the strength member's bottom bronze fitting and strain relief boot. Using a pair of pipe pliers, ease the orange termination boot away from the bronze fitting exposing the wire rope. Place the slip bale (bale facing up towards the surface package) on the wire rope, slide the bale onto the bronze fitting until it rests against the Delrin clamp, and tighten the $3 / 8$ " bolt. Be sure to slide the orange boot back until it rests against the bottom of the slip bale. 
The process of slipping the mooring until the surface package is placed on top of the deployment hole is the most important portion of the deployment operation and extreme care should be taken. You must be able to slowly and comfortably lower the mooring using the 'Yale Grip' as the lowering point.

The following roles need to be performed by various team members for the final step to install the surface package:

a. One member tends the 'Yale Grip' which is loosened to control the pay out of the mooring.

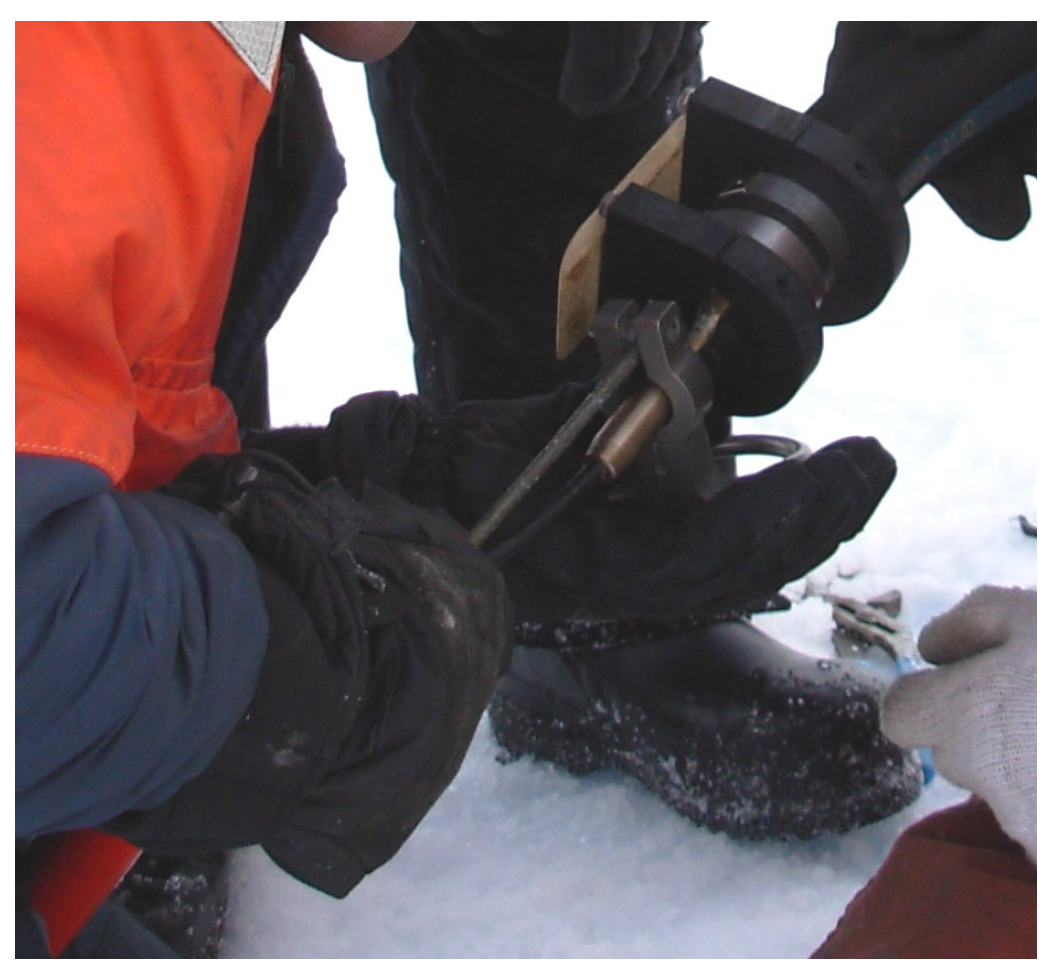

Figure 12: Attaching slip bale to cable.

b. A second member controls the $3 / 8$ " VLS slip line and slip bale.

c. The third team member manages the coil cord strength member to aid it down the hole.

d. If available, a fourth member may carefully aid the surface package along the ice and position it on the deployment hole.

When the team is ready and in place, the team member responsible for the 'Yale Grip' begins to take the electrical tape off of the bottom tails, making sure that one hand is constantly holding and keeping downward pressure. Once the tape is off, both hands are used to begin to unravel the tails from the braided grip. When enough of the 'Yale Grip' tails have been 
unraveled (normally half way to the eye), the $1 / 4$ " wire will begin to slowly slip. As soon as this occurs, grab all four tails and pull down towards the ice, thus stopping the mooring and to get a feel for the control. Do not clamp your hands on the braid for it will not stop the mooring. Instead, you must pull down on the four grip tails. At this time, this team member is holding the entire mooring. To allow the mooring to slip again, slowly and carefully ease off on the downward pressure. Continue to slip the mooring until the SS slip bale is hanging vertically adjacent to the chain hoist's hook.

The team member responsible for slipping the mooring using the slip bale and VLS line should tie a bowline onto an unused 5/8" pear ring on the tripod clevis. Run the bitter end of line through the slip bale, back up through the $5 / 8$ " pear ring and then down to the cleat which is bolted to the tripod leg. Before making the line fast, take up the additional slack in the line. The 'Yale Grip' is then slowly loosened causing the VLS line and the slip bale to take the load of the mooring. Take the grip completely off the wire rope. The slip line tender slips the mooring further using the cleat until the buoy is on top of the hole. A team member must pull back on the buoy in order to clear the VLS line from the slip bale and eventually the deployment hole. Once the line is clear and the buoy is flat on the ice, the mooring is deployed.

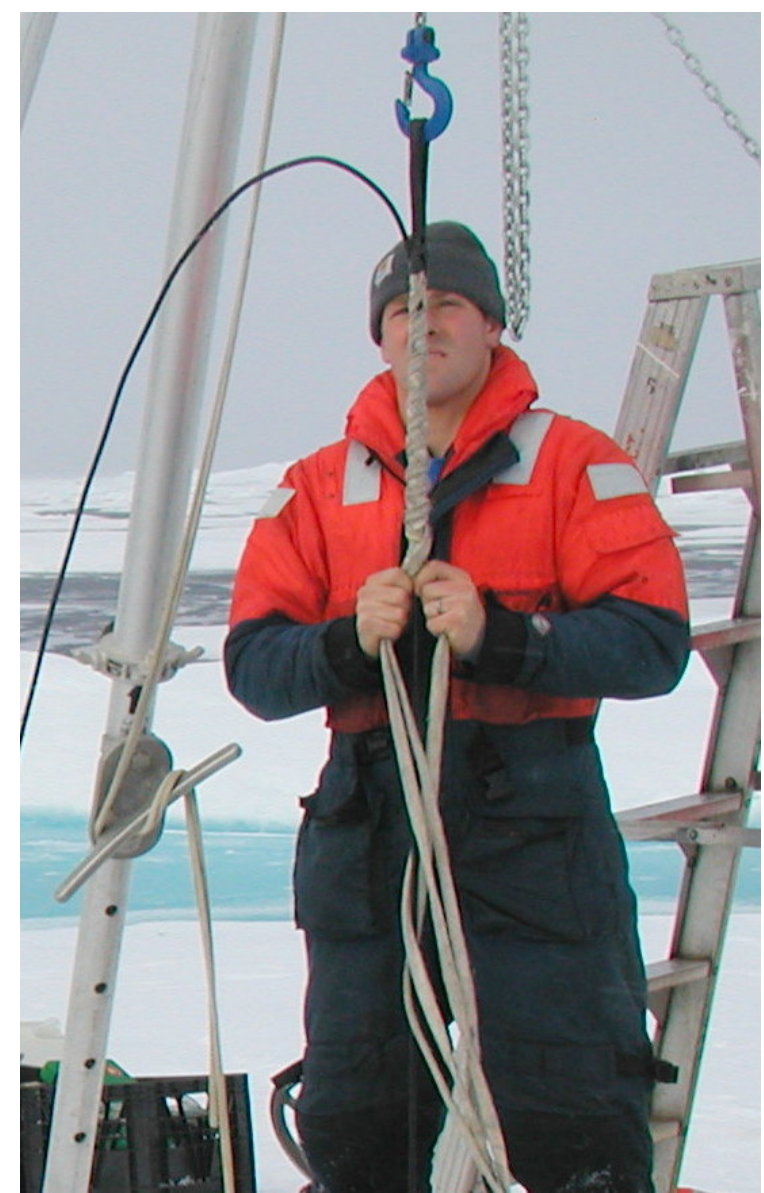

Figure 13. A 'Yale Grip' is used to slip the mooring until the slip bale is adjacent to the 'Yale' grip. 


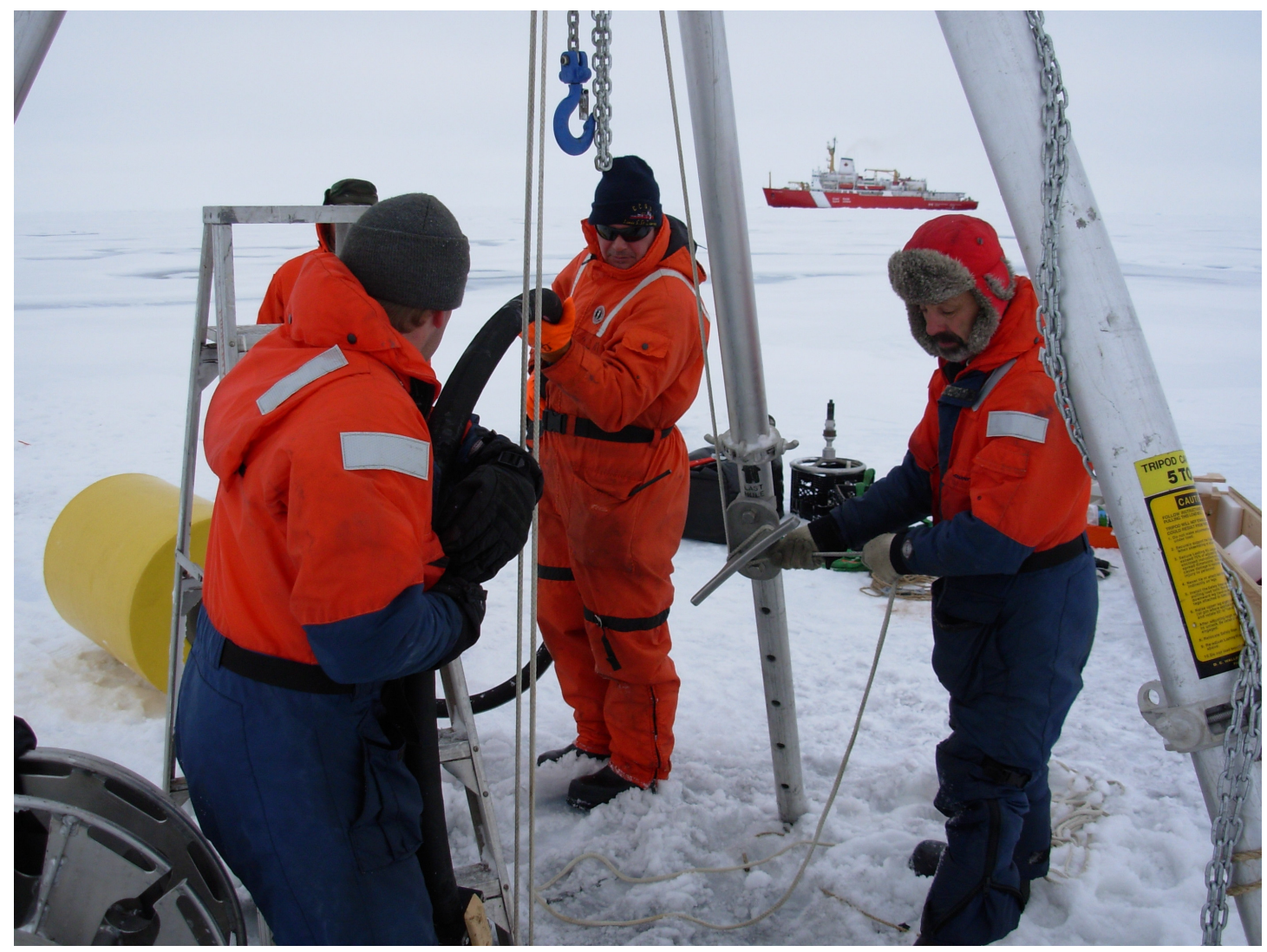

Figure 14: Using the cleat to slip the final section of the mooring into place. The rope at the cable end loops through the slip bale connection on the cable.

\section{POST DEPLOYMENT:}

Once the ITP has been deployed, the inductive modem link between the surface package and profiler can be tested while site clean up takes place.

\section{Inductive Modem Test:}

When everything is connected and installed, the inductive modem circuit that establishes communications between the profiler and surface package is complete. Between the time that the profiler is configured for deployment and it begins its first profile (down), the profiler leaves its tone detector on, so it can receive a prompt from the surface package. In order to test the integrity of the communications between the surface controller and profiler through the inductive 
modem circuitry, a laptop computer (with serial port and terminal emulator program) can be used to connect to the surface controller, break out of the SURFCON program, and run the XBT board test program. The "u" command in XBT starts the surface inductive modem (SIM) and prompts the profiler underwater inductive modem (UIM). The SIM is a SeaBird SBE-37 and the UIM is an SBE-44. Refer to ITP technical report WHOI-2006-11 (Krishfield et al., 2006) for details on the operation of the ITP SURFCON.

A sample successful response from an ITP deployed in 2006 documents the steps of the procedure:

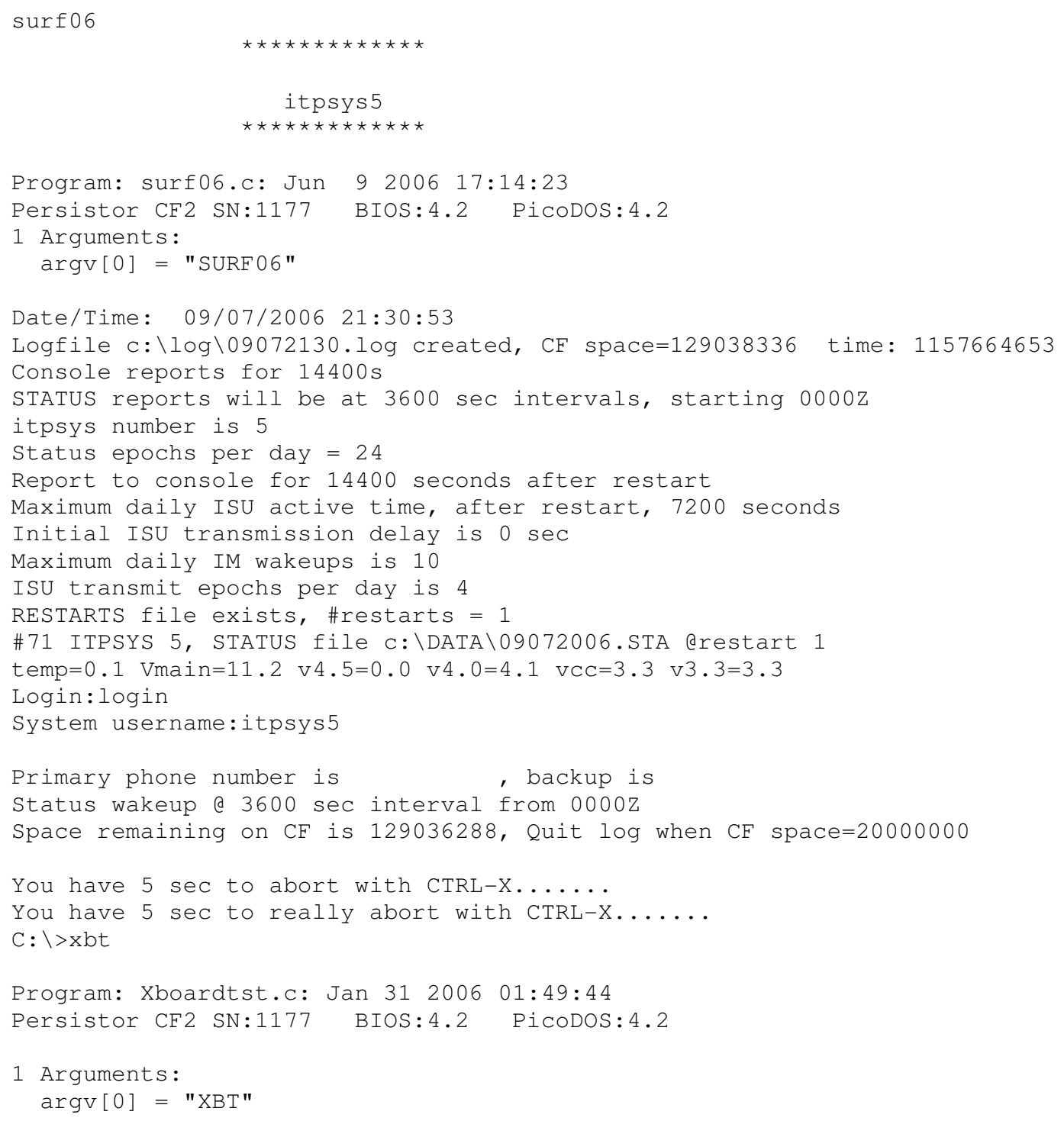




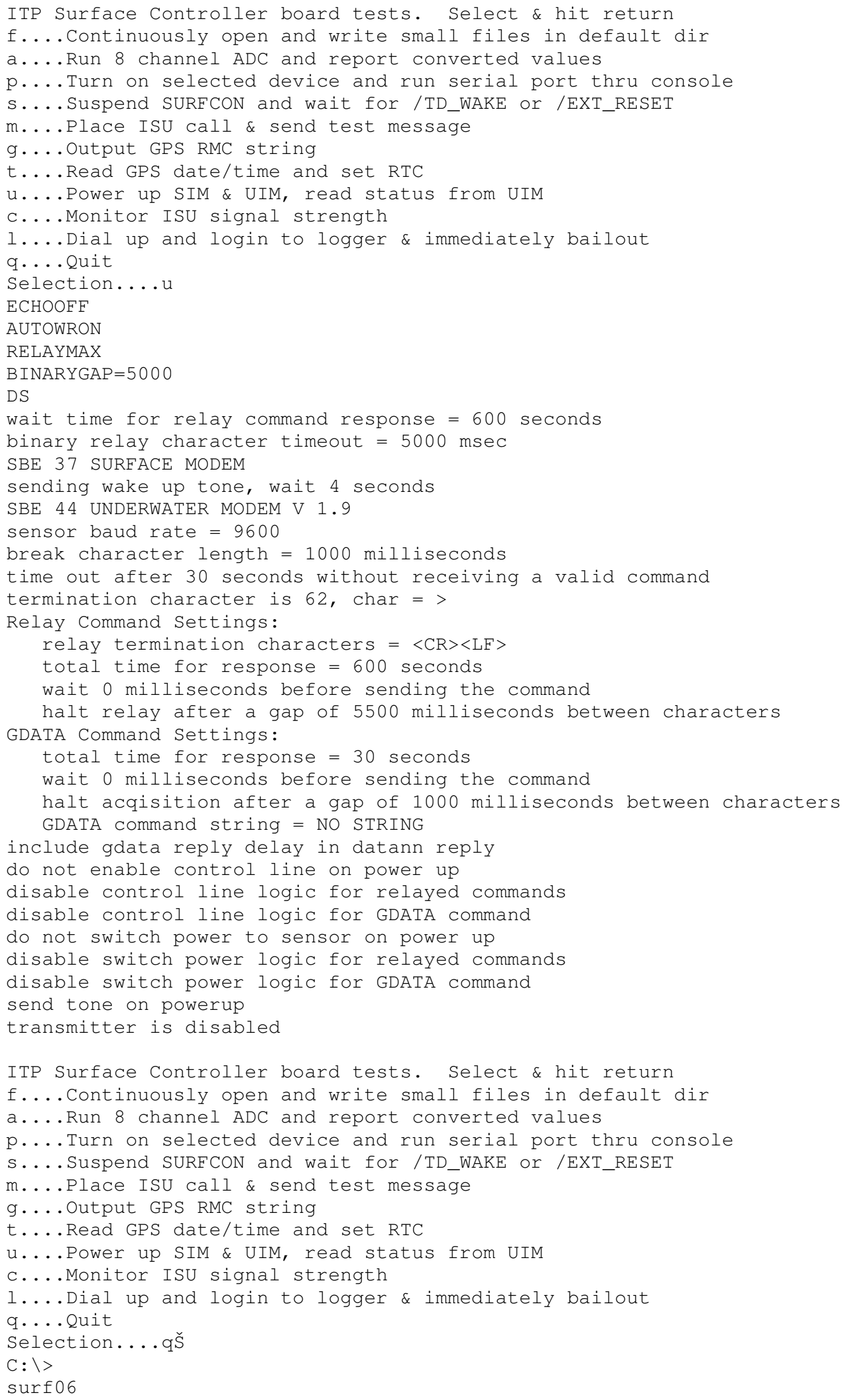




\section{Site Breakdown and Clean Up:}

Disassembly procedures can commence immediately after deployment and while testing of the inductive modem is in process. The deployment apparatus can be taken down and stored away from the surface package for transport back to the ship. The winch can be left assembled and rigged for slinging; making sure the ratchet strap is secured before transport. All gear when being staged on the ice for the transfer back to the ship should be covered or secured to the ice when the helicopter is in motion. Any gear left unattended could potentially get blown into the helicopter's blades and cause significant safety problems. Before leaving the site, place four pieces of $3 / 4$ " plywood under the surface package and cover with snow. It is important to completely cover the plywood with clean snow for black and dirty snow can cause increased melting due to absorption of solar radiation.

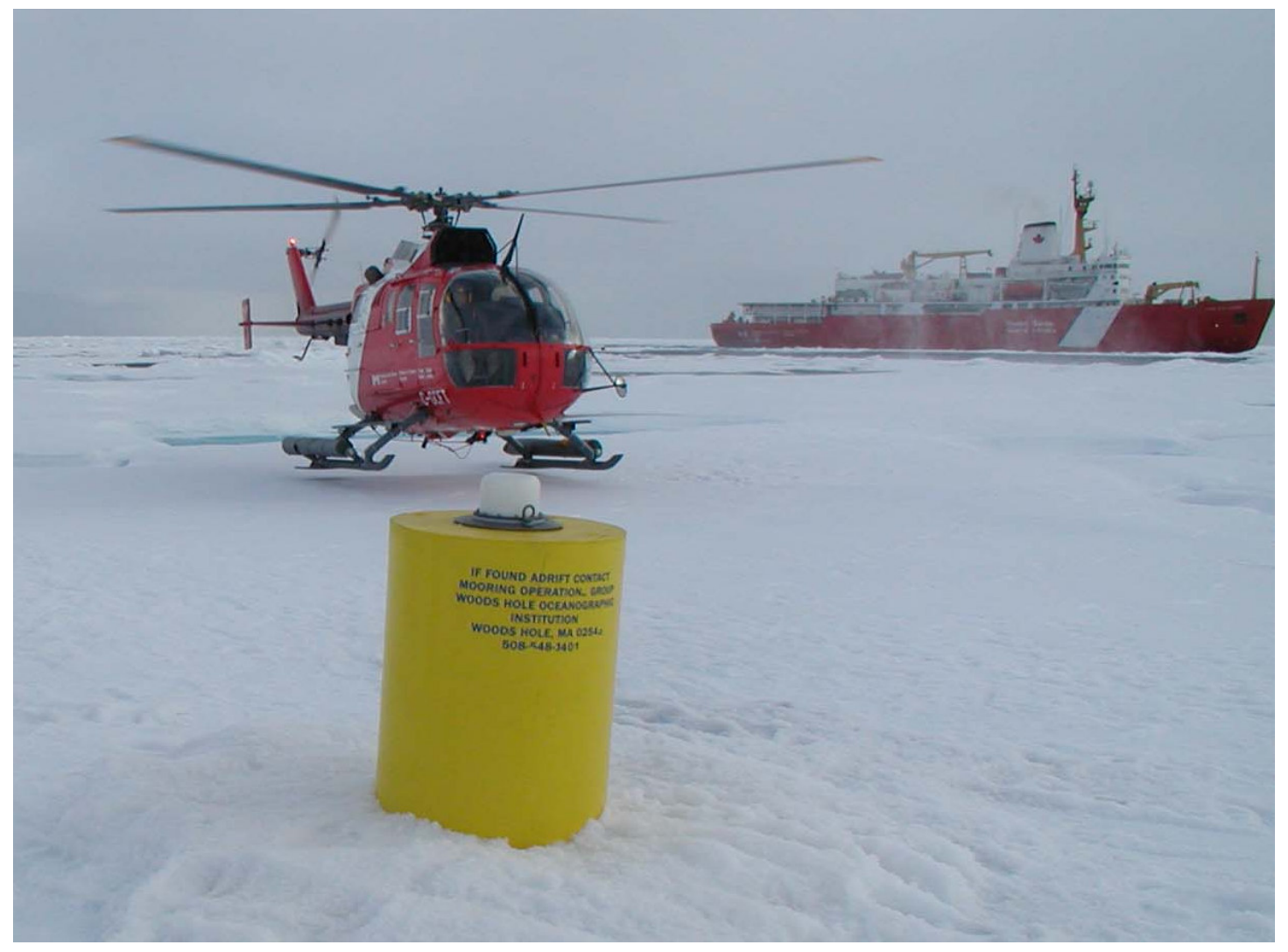

Figure 15: Finishing touches on the deployment site 


\section{CONCLUSIONS}

With proper site selection techniques, instrument testing, and knowledgeable and efficient field operations, ITP systems can be deployed successfully on multiyear pack ice using icebreakers, helicopters, and from air supported ice camp operations in the Arctic Ocean.

In order to extend the profiling capability of the ITP system, an accurate and in-depth site survey and analysis is the first critical step. The use of satellite imagery, if available, provides the best opportunity for finding a suitable floe, but sometimes visual observations from a ship or an aircraft must suffice. If the proposed testing site is on $1^{\text {st }}$ year ice, multiyear ice less than 1.5 $\mathrm{m}$ thick, or in a field of ridges, cracks, or melt ponds, then time should be spent finding an alternate. Finding the best available site within the time constraints provided will give the ITP system the best possible chance for a lengthy profiling life span.

It is highly recommended to power and test the surface package for a substantial amount of time before deployment. Days before deployment, the batteries may be connected and the internal electronics re-inserted into the inner housing, and the unit(s) may be left outside and in clear view of the satellites to acquire GPS locations and verify the Iridium link is working properly. Then, once deployment procedures have been completed, testing of the Inductive Modem link is also suggested. Using a terminal emulator program, the operator may prompt the ITP profiler through the ITP surface controller, by temporarily breaking out of the surface controller program and using the boardtest program (XBT.PXE) obtain a response from the profiler, to verify that the tether transmissions are working properly.

The assembly and disassembly techniques of the ITP winch system should be practiced before deployment operations by all mooring team members to enhance productivity and efficiency while on the ice. If using a helicopter, the winch can be slung as one assembled unit; 
however if using a ship's basket or from an ice camp, the winch can and should be taken apart and moved around the ice on sleds. Once the winch and deployment apparatus is assembled and on the ice, time should be spent to properly place the winch in relation to the hole.

The 'Yale Grip' braiding and slipping techniques are needed to handle the most critical junction throughout the deployment, when the load of the entire mooring is transferred to the surface package. Experience or practice implementing the 'Yale Grip' on wire rope is advised prior to the actual deployment to ensure smooth load handling.

The most important steps in the ITP deployment procedure are listed in the Appendix. 


\section{AKNOWLEDGEMENTS}

On behalf of the entire WHOI mooring and science team members who participated on the JWACS/BGEP cruises on the Louis S. St-Laurent in August of 2004, 2005, and 2006, we would like to express our heartfelt gratitude towards the Captains, officers, and crew members for their professionalism and skill to successfully aid in achieving our science goals. We identify that without the knowledge and experience of the ship's personnel, our science objectives may not have been achieved in one of the most remote areas of the Arctic Ocean. Specifically for the 2006 cruise, we would like to thank Captain Andrew McNeill for his attentiveness and impressive ship handling ability and Helicopter Pilot Chris Swannel for his enthusiasm and professionalism. We acknowledge the contributions and efforts of the officers and crew and other scientists on the CCGS Louis S. St. Laurent during the JWCAS cruises since 2003 to the WHOI development of an efficient and successful method for deploying the ITP system. Initial development of the ITP concept was supported by the Cecil H. and Ida M. Green Technology Innovation Program. Funding for construction and deployment of the prototype ITPs was provided by the National Science Foundation Oceanographic Technology and Interdisciplinary Coordination (OTIC) Program and Office of Polar Programs (OPP) under grant number OCE0324233. Continued support has been provided by the OPP Arctic Sciences Section under award numbers ARC-0519899 and ARC-0631951, and internal WHOI funding. Any opinions, findings, and conclusions or recommendations expressed in this publication are those of the authors and do not necessarily reflect the views of the National Science Foundation. 


\section{REFERENCES}

Kemp, J., K. Newhall, W. Ostrom, R. Krishfield, and A. Proshutinsky, 2005, The Beaufort Gyre Observing System 2004: Mooring Recovery and Deployment Techniques in Pack Ice, WHOI Technical Report: WHOI-2005-05.

Krishfield, R., K. Doherty, D. Frye, T. Hammar, J. Kemp, D. Peters, A. Proshutinsky, J. Toole, and K. von der Heydt, 2006, Design and Operation of Automated Ice-Tethered Profilers for Real-time Seawater Observations in the Polar Oceans, WHOI Technical Report: WHOI-2006-11.

Toole, J., R. Krishfield, A. Proshutinsky, C. Ashjian, K. Doherty, D. Frye, T. Hammar, J. Kemp, D. Peters, M.-L. Timmermans, K. von der Heydt, G. Packard, and T. Shanahan, 2006, Ice Tethered-Profilers Sample the Upper Arctic Ocean. EOS, Transactions of the American Geophysical Union, Vol. 87, No. 41: 434, 438. 


\section{APPENDIX: ITP DEPLOYMENT CHECKLIST}

\section{Pre-deployment preparations (at least several days before):}

- Unpack ITP buoy and breakdown box for creating palette during deployment.

- Disassemble ITP surface buoy, power electronics while capturing to disk, reassemble.

- Disassemble ITP profiler, power electronics while capturing to disk, reassemble, and bench test.

- Monitor daily ITP transmissions for correct GPS locations and buoy status.

- Stage tripod/winch apparatus and handling gear for transport to deployment site (the 10" auger flights (w/ 11" blade) and Jiffy head, with gas and extensions, should be the first item out so that the deployment hole can be cut while other equipment is being transferred).

\section{Ice floe reconnaissance:}

○ Prepare 4' Akio sled with 2" hand auger and extensions, ice measuring tape, screwdriver, shovel, and site markers for surveying ice floe thickness.

○ Search for a site between 2.5 and $4 \mathrm{~m}$ thick, on a high spot (hummock) in homogenous ice (not located on an old ridge), and away from as many ridges, cracks, and melt ponds as possible.

\section{After site selected:}

○ Configure ITP profiler while capturing to disk.

\section{Deployment:}

- Transport personnel and equipment to site.

○ Drill 11" diameter hole completely through the selected ice floe using 10" auger with long bit, and extensions. If drilling becomes difficult, hang auger from tripod and lower with chainfall to reduce the labor.

- Lower pipe segment $\sim 9 \mathrm{~m}$ through hole to make sure there are no false bottoms or rafted ice floes underneath.

- Cover hole with plywood. Set up tripod and winch, and load spool with wire rope.

- Attach anchor to end of wire, and hang over hole. Remove plywood.

$\circ$ Attach bottom bumper $\sim 1 \mathrm{~m}$ above wire termination.

$\circ$ Lower the anchor through the hole and pay out 10-20 $\mathrm{m}$ of wire.

- Position so that the wire will be skewed to one side of the hole to facilitate deployment of the profiler.

○ Unpack and hang ITP profiler next to wire using clove hitch. 
- Remove profiler guide collars and modem magnet (do not lose magnet core), and reattach around wire (do not over tighten nylon bolts or else could break in cold).

- Remove CTD sensor caps and verify that plugs are installed.

- Clear hole of as much ice and slush as possible.

- Remove clove hitch and lower profiler through the hole. Push gently with shovel handle (on clamps, not sensors) if it binds to the edges.

- Pay out wire under control until roughly 1 layer or wire rope remains on the width of the reel.

- Use a Yale grip on the wire and chain hoist on the tripod to take the mechanical load. The wire should not slip.

- Unspool the potted section of the wire, stretch out, and remove protective plastic tubing.

$\circ$ Remove flange from buoy and mechanically connect the potted cable to the flange using 2 large 1/2" bolts with inserts (use 2 SS $1 / 2$ " nuts per bolt).

- Make electrical connections to the buoy (using a little grease, and heating connector ends with heat pack if necessary), and mechanically connect flange with $1 / 4-20$ bolts with inserts.

- Attach grounding plate with bracket to potted cable junction, pull back termination boot, install slip bale, and reinstall boot.

- Secure 3/8" VLS slip line from tripod clevis to slip bale and wrap a few turns around cleat. One person to remain on slip line at all time.

- Slip Yale grip until potted cable junction is over hole. Take load with slip line and remove Yale grip.

- Attach top bumper $\sim 1 \mathrm{~m}$ below cable junction.

- Slip mooring until ITP buoy rests on hole.

- Pivot buoy to remove slip line.

\section{Post-deployment operations:}

○ Test inductive modem (IM) link while capturing to disk.

- Ensure that dummy connector is installed on communications connector and connectors are pushed into foam cavity.

- Build palette under buoy and cover with snow.

- Break down tripod/winch apparatus, clean area of debris, and transport everyone and everything back.

○ Celebrate. 
50272-101

\begin{tabular}{|c|c|c|}
\hline $\begin{array}{l}\text { REPORT DOCUMENTATION } \\
\text { PAGE }\end{array}$ & 1. REPORT NO. & 3. Recipient's Accession No. \\
\hline \multirow{2}{*}{\multicolumn{2}{|c|}{$\begin{array}{l}\text { 4. Title and Subtitle } \\
\text { Deployment Operation Procedures for the WHOI Ice-Tethered Profiler }\end{array}$}} & $\begin{array}{r}\text { 5. Report Date } \\
\text { July } 2007\end{array}$ \\
\hline & & 6. \\
\hline \multicolumn{2}{|c|}{ 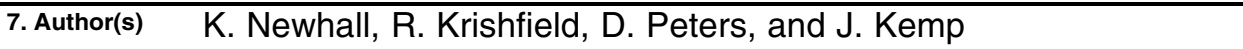 } & 8. Performing Organization Rept. No. \\
\hline \multirow{4}{*}{\multicolumn{2}{|c|}{$\begin{array}{l}\text { 9. Performing Organization Name and Address } \\
\text { Woods Hole Oceanographic Institution } \\
\text { Woods Hole, Massachusetts } 02543\end{array}$}} & 10. Project/Task/Work Unit No. \\
\hline & & $\begin{array}{l}\text { 11. Contract(C) or Grant(G) No. } \\
\text { (C) OCE- } 0324233\end{array}$ \\
\hline & & (G) ARC-0519899 \\
\hline & & ARC-0631951 \\
\hline \multicolumn{2}{|c|}{ 12. Sponsoring Organization Name and Address } & 13. Type of Report \& Period Covered \\
\hline \multirow{2}{*}{\multicolumn{2}{|c|}{ National Science Foundation }} & Technical Report \\
\hline & & 14. \\
\hline
\end{tabular}

15. Supplementary Notes

This report should be cited as: Woods Hole Oceanog. Inst. Tech. Rept., WHOI-2007-05.

16. Abstract (Limit: 200 words)

Deployed and fixed to a suitable multi-year ice floe, the Ice-Tethered Profiler (ITP) can sustain near-real time measurements of upper ocean temperature and salinity for up to three years. Incorporating a specifically designed winch system and deployment apparatus that is both lightweight and easily assembled or disassembled on a ship or at a deployment site, the ITP can be deployed in less than four hours by either transporting the gear and field personnel to the deployment site via aircraft, or by lowering the gear over the side of a ship and hauling on the ice. Using daily satellite imagery (if available), visual reconnaissance flights, and ice surveying, the choice of an appropriate ice floe is a necessity to select a site that will sustain the system for a prolonged period of time (depending upon the instrument sampling rate). If available, the helicopter is the preferable method for suveying different sites and for deployment operations. Working from a ship typically limits the distance and selection of ice floes. Pre-deployment procedures include powering and configuring the ITP instruments and preparing the apparatus for transport to the deployment site. Specific deployment methods include the assembly and disassembly of the ITP winch, proper placement of the total ITP deployment apparatus, "Yale Grip" braiding and slipping techniques, and testing the Iridium and inductive communication links. The operations described here provide a safe and efficient manner to easily deploy the WHOI ITP.

\section{Document Analysis a. Descriptors}

Arctic/Ice Deployments

Winch/Tripod Apparatus

Ice Tethered Profiler

b. Identifiers/Open-Ended Terms

c. COSATI Field/Group

18. Availability Statement

Approved for public release; distribution unlimited.

\begin{tabular}{|l|l|}
\hline $\begin{array}{c}\text { 19. Security Class (This Report) } \\
\text { UNCLASSIFIED }\end{array}$ & $\begin{array}{c}\text { 21. No. of Pages } \\
48\end{array}$ \\
\hline 20. Security Class (This Page) & 22. Price \\
\hline
\end{tabular}

